\title{
Customer-Oriented Employees: Blessing or Curse for Firms?*
}

\author{
Ester Manna ${ }^{\dagger}$
}

May 16, 2017

\begin{abstract}
I investigate whether the presence of customer-oriented employees benefits firms in a competitive environment. Employees are defined as customer-oriented if they are interested not only in their wage but also in the well-being of their customers. I find that firms may obtain higher profits by hiring self-interested rather than customer-oriented employees. This is because the employees' customer orientation has opposing effects on the profits obtained by the firms. On the one hand, customer-oriented employees provide a given level of quality for a lower wage. On the other hand, the employees' customer orientation increases competition reducing prices. If the second effect dominates, firms find themselves trapped in a prisoners' dilemma as the strategy of hiring self-interested employees is strictly dominated by that of hiring customer-oriented employees. Hence, the very presence of customer-oriented employees may hurt firms. If motivated employees are merely interested in the quality of the good provided, the effect on the price outlined before disappears.
\end{abstract}

Keywords: Spatial Competition, Customer-Oriented Employees, Prisoners' Dilemma, Altruism, Vertical and Horizontal Differentiation.

JEL classifications: D03, D21, L13.

*I would like to thank the editor, Ramon Casadesus-Masanell, a co-editor, and three anonymous referees for very helpful and constructive comments. This article is based on the first chapter of my Ph.D. dissertation at the Université libre de Bruxelles, ECARES. I am particularly indebted to Georg Kirchsteiger for his careful supervision and continuous support. I am thankful to Tommaso Aquilante, Francis Bloch, Lídia Brun, Estelle Cantillon, Marcello D’Amato, Alessandro De Chiara, Florian Englmaier, Guido Friebel, Alexander Groves, Tobias Kretschmer, Patrick Legros, Luca Livio, François Maniquet, Guido Maretto, Martin Peitz, Salvatore Piccolo, Amedeo Piolatto, Fernando Sanchez, Philipp Schmidt-Dengler, Marc Teignier, Thierry Verdier and Montserrat Vilalta for a number of insightful comments and useful observations. I also wish to thank audiences at the University of Cologne, Ludwig-Maximilian-Universität München, Universitat de Barcelona, University of Mannheim, ECARES Seminar, University of Salerno, FAU Erlangen-Nürnberg, and at a number of conferences and workshops for useful comments and discussions. Finally, I acknowledge the financial support of the Government of Catalonia through grant 2014SGR493. This paper supersedes an earlier working paper titled: "Intrinsically Motivated Agents: Blessing or Curse for Firms?" The usual disclaimer applies.

${ }^{\dagger}$ Universitat de Barcelona, Department of Economics, Avinguda Diagonal 696 (08034), Barcelona, Spain. Email: ester.manna1@gmail.com; estermanna@ub.edu. 


\section{Introduction}

Customer-oriented employees are interested not only in their wages, but also in satisfying customers' needs. It is natural to think of these workers as employed in non-profits organizations or in the public service provision, such as the health care and education sectors (see for example Francois, 2000, Biglaiser and Ma, 2007, and Delfgaauw and Dur, 2008). However, profit-maximizing firms can also attract customer-oriented employees by offering them jobs that have a valuable impact or a socially oriented mission. Psychologists and marketing scholars argue that this is more likely to be the case in the service sector, where there is a strong interaction between customers and employees. ${ }^{1}$ The marketing literature also finds a positive relationship between the employees' customer orientation and the customers' satisfaction. ${ }^{2}$ For this reason, the employees' customer orientation is considered to be an important factor for service firms' economics success (see Bove and Johnson, 2000, and Sergeant and Frenkel, 2000). Therefore, firms may want to have a customer-oriented workforce to satisfy customers' needs in an attempt to win market shares and increase profits.

In the economics literature, the impact of employees' customer orientation on the customers' satisfaction and on the firms' profits has not yet been studied. Although it may come as a foregone conclusion that profit-maximizing firms would be better off if their customers are more satisfied, this relationship is in fact far from being obvious. The main contribution of this article is to show that in the presence of competition the strategic interaction between firms may lead to surprising results concerning the desirability of hiring customer-oriented employees. Firms may obtain higher profits by hiring self-interested rather than customer-oriented employees. However, they find themselves trapped in a prisoners' dilemma as the strategy of hiring self-interested agents is strictly dominated by that of hiring customer-oriented agents. In other words, firms end up hiring customeroriented employees even when they would prefer to coordinate and hire selfish employees, but they cannot credibly commit to that.

To model competition, I use a Salop model where profit-maximizing firms offer both horizontally and vertically differentiated products ${ }^{3}$ and decide whether to hire selfish or customer-oriented employees. While the utility function of a selfish employee only depends on his "egoistic" payoff (given by the difference between the wage and the cost of exerting

\footnotetext{
${ }^{1}$ Saxe and Weitz (1982) are the first to describe a concern for customers in the service sector and then Hogan et al. (1984) have defined employees' service orientation as "a set of attitudes and behaviors affecting the quality of interaction between an organization's employees and its customers".

${ }^{2}$ Hennig-Thurau (2004) tests empirically a sample of 989 consumers for two service sectors (i.e. book/CD/DVD retailers and travel agencies). This author finds a positive relationship between customerorientation and customers' satisfaction. For related studies see also Hennig-Thurau and Thurau (2003) and Donavan et al. (2004).

${ }^{3}$ Restaurants are a suitable example of a sector offering horizontally and vertically differentiated products. Restaurants offer different menus, i.e. products are horizontally differentiated. In addition, the quality provided by the restaurants is different and is affected by the effort exerted by their own employees, i.e. products are vertically differentiated.
} 
effort), the utility function of a customer-oriented employee also positively depends on the customers' well-being. The baseline model is analyzed under the assumption of perfect information on the employees' type. But the main results are robust when this assumption is relaxed.

The employees' customer orientation has conflicting effects on the firms' profits at the equilibrium. On the one hand, the presence of customer-oriented employees has a positive effect on profits thanks to a wage reduction. Customer-oriented employees provide goods of a given level of quality for a lower wage. This is because the agent's customer orientation reduces the agent's marginal cost of eliciting effort. On the other hand, it has a negative impact on profits through a reduction in the price of the products offered by the firms. When the employees care about the customers' well-being, the employees' utility decreases if the firm decides to charge a higher price. The agent's customer orientation makes employees more sensitive to prices and qualities, thus forcing firms to compete more fiercely and to lower their prices. This latter effect can be large enough to outweigh the gain generated by lower wages.

When the negative effect on the profits dominates, firms find themselves trapped in a prisoners' dilemma, and the presence of customer-oriented employees hurts firms. Which effect dominates is crucially affected by the degree of competition in the market. Specifically, the prisoners' dilemma is more likely to occur in markets with less substitutable products and fewer firms. Therefore, when the market is more concentrated, firms would be better off hiring selfish agents.

As for the impact of the employees' customer orientation on the customers' welfare, this is unambiguously positive when the number of firms is exogenous. A higher degree of employee's customer orientation increases competition reducing the price charged by the firms. However, this positive effect of the employees' customer orientation on the customers' well-being may be mitigated or become negative when the number of firms is endogenous. This is because fewer firms enter the market when the gross profits obtained by hiring selfish agents are higher than those obtained by hiring customer-oriented agents. Because of horizontal differentiation a wider variety of goods is beneficial to customers.

It is important to notice that a monopolistic firm always benefits from hiring a customer-oriented employee. A higher customer orientation induces the monopolistic firm to increase both quality and price. For each unit of the product which is sold, the firm is able to charge a higher price to reflect the higher product quality. Crucially, the monopoly is also able to attract new customers and enjoys an increase in the demand. In contrast, when there is competition, by offering a more valuable product firms do not attract additional customers. This is because firms follow the same strategy and, as a result, they share the demand in the market.

The key assumption of this article is that motivated employees are not only interested in their "egoistic" payoff but also in the customers' well-being. In other words, these employees have altruistic preferences towards their customers. ${ }^{4}$ More specifically, in my

\footnotetext{
4 "A person is altruistic if her utility increases with the well-being of other people" (Fehr and Schmidt,
} 
model, motivated employees exhibit pure altruism because they internalize in their own utility the effects that both prices and quality entail for customers' utility. When this is the case, employees also care about the price charged by the firms and the firms can extract a lower amount of surplus from their customers for any given level of quality. This stands in contrast with impure altruism which would lead to a model where motivated employees derive utility from the quality of the good they provide. If motivated employees were merely interested in the quality of the goods/services, the strategic effect on the price outlined before would disappear. Therefore, whether these motivated employees have pure or impure altruistic preferences leads to dramatically different conclusions concerning the desirability of hiring a motivated workforce.

Since the main results of the paper crucially depend on the employees' interest in the customers' well-being rather than just in the quality of the good provided, the analysis calls for additional empirical studies to investigate what drives employees' actions. The existing experimental evidence is mostly consistent with the assumption of impure altruism (see among others Tonin and Vlassopoulos, 2010, 2015, Imas, 2014, and Charness et al., 2016). However, some experimental and empirical studies have found supportive evidence for pure altruistic motives or for both forms of altruism (see Konow, 2010, Gregg et al., 2011, Lilley and Slonim, 2014, and Ottoni-Wilhelm et al., 2014).

The remainder of the article proceeds as follows. In the next section the related literature is reviewed; in Section 3 the model is presented and a monopolistic environment is analyzed; in Section 4 the equilibrium of the model is characterized for a given number of firms; in Section 5 the conditions under which the prisoners' dilemma arises are illustrated; in Section 6 some robustness checks are studied; concluding remarks and discussion of the results are given in Section 7.

\section{Related Literature}

This article is related to the literature on psychological incentives and to the one on the effects of competition on managerial incentives. The former focuses on the existing interaction between intrinsic motivation and monetary incentives without considering the role played by competition in shaping the monetary incentives of the employees. The latter focuses on the impact of competition on the incentives without considering potential differences in the agents' preferences. I bridge these two strands of the literature by considering the interaction between monetary incentives and the agents' motivation in a competitive environment.

The economics literature on psychological incentives shows that employees derive nonmonetary benefits from providing some types of services (see Biglaiser and Ma, 2007,

2006). This hypothesis has a long tradition in economics and may account for charitable donations and the voluntary provision of public goods (see for example Andreoni and Miller, 2002). In Andreoni (1989, 1990), the author argues that there may be other motives to contribute to the public good, such as social pressure, guilt, or a desire of "warm glow", and he distinguishes between pure and impure altruism. 
Buurman et al., 2012, and Dur and Zoutenbier, 2014). The idea is that employees care about the recipients of the service, i.e. they are worried about the welfare of their patients, students, or customers. This idea has mainly been referred to public service employees (see among others Bond and Glode, 2011, and Jaimovich and Rud, 2014). In particular, most studies have argued that public service employees are eager to serve the others and satisfy the customers' needs (see Francois, 2000, 2007, Glazer, 2004, and Macchiavello, 2008). As a result, this literature has emphasized how, especially in the public service or non-profit sectors, the employers can extract labor donations from motivated employees (see Francois and Vlassopoulos, 2008, for a survey). ${ }^{5}$ While these articles study the sorting of differently motivated people into public sector and its consequences for optimal pay policies and organizational design, I study how the presence of customers' oriented employees impacts on firms' profits and customers' well-being. Moreover, there are some remarkable differences in how this "pro-social" motivation is included in the employees' utility function. In some articles, the motivation component is represented as a function of the effort exerted by the employee with a positive first derivative. That is, an employee directly benefits from increasing his own level of effort, or, equivalently, the employee has a lower marginal cost of exerting effort. In Besley and Ghatak (2005) for example the employees' effort costs are low when they share the firm's mission. ${ }^{6}$ In other articles, employees care about the quality of the good that is provided. For example, in Francois (2007) the employees derive a benefit when the good provided is deemed socially valuable. One remarkable departure of my model from the literature on psychological incentives is that employees can be interested in the customers' well-being rather than in the quality per se. When this is the case, employees are more sensitive to prices and qualities, thus forcing firms to compete more fiercely and to lower their prices. This reduction in the price can be sufficiently large as to outweigh the gain engendered by the reduction in wages. $^{7}$

This article is also related to the literature on the effects of competition on managerial incentives. ${ }^{8}$ Particularly close is Raith (2003), wherein the author examines how the

\footnotetext{
${ }^{5}$ Gregg et al. (2011) use data from the British Household Panel Survey (BHPS) and show that individuals in the non-profit sector are significantly more likely to do unpaid overtime than those in the for-profit sector.

${ }^{6}$ Besley and Ghatak (2005) also consider a competitive environment but the main objective of their analysis is to study the self-selection of different types of agents between different types of sectors.

${ }^{7}$ Consistently with the psychological literature, customer-oriented employees provide a given level of effort for a lower wage. Some articles in this literature also suggest that monetary incentives can have a negative impact on the effort exerted by motivated employees. For instance, monetary incentives may change how tasks are perceived by agents (Benabou and Tirole, 2003) and/or they may reduce the value of generous or civic minded acts as a signal of one's moral character (Gneezy and Rustichini, 2000a, and Benabou and Tirole, 2006). If extrinsic incentives are not large enough, this change in perception can even lead to undesired effects on individuals' behavior (Gneezy and Rustichini, 2000b).

${ }^{8}$ Hart (1983) is the first to model the effect of competition on the agency problem between a firm's owner and a manager. Scharfstein (1988) reconsiders Hart's model relaxing the assumption of infinitely risk-adverse managers. Hermalin (1994) considers additional effects of competition on the agency problem,
} 
degree of competition among firms in an industry with free entry and exit impacts on the wages paid to their employees. The effect of competition on wages and effort takes place through a change in the equilibrium number of firms in the industry. The results suggest an unambiguous positive relationship between competition and wages. Like Raith (2003), this article shows that competition increases the wages paid to self-interested agents. When products are more substitutable, prices and profits decrease leading to fewer firms. Each firm produces a higher level of quality and each agent receives a higher wage. However, when agents are customer-oriented there is an additional effect that goes in opposite direction. If products are less substitutable, customers are worse off and firms have to pay higher wages to customer-oriented agents to keep the level of quality constant.

Baggs and De Bettignies (2007) also study how product market competition affects employee effort and firm efficiency. They show that the impact of competition differs depending on whether or not they are subject to agency costs. Similar to their paper, I use a spatial competition model in which firms offer both horizontally and vertically differentiated products.

Finally, the results of my paper are to some extent linked with those presented in Fershtman and Judd (1987). In a Cournot model, these authors show that owners offer incentives to their managers which depend also on sales, even though they would have been better off providing incentives based just on profits. Thus, firms find themselves trapped in a prisoners' dilemma concerning which incentive contract they offer to their employees. Conversely, in my article the prisoners' dilemma pertains to the type of employee that is hired. Moreover, the result of Fershtman and Judd (1987) is driven by the existence of asymmetric information between owners and employees about demands and/or costs. Therefore, they shed light on how the presence of asymmetric information distorts incentives away from efficiency. In contrast, I highlight how the presence of customer-oriented agents can hurt firms in a complete information setting. ${ }^{9}$ There is no need to add any informational friction in the model to attain the prisoners' dilemma.

\section{The Model}

A continuum of customers of mass 1 is distributed uniformly on a Salop circle (Salop, 1979), whose perimeter is normalized to 1 . Each customer buys exactly one unit of the good. There are $n$ profit-maximizing firms that operate in the market and that are positioned equidistantly around the circle. ${ }^{10}$ The products offered by the firms are horizontally differentiated. Each firm consists of a principal and an agent, both risk neutral. The principal-agent relationship can be interpreted as the relationship between

\footnotetext{
all of which are of potentially ambiguous sign. Schmidt (1997) shows that greater competition may lead to stronger incentives for agents because greater effort is required to avert the threat of bankruptcy.

${ }^{9}$ In addition, the equilibrium inefficiency in Fershtman and Judd (1987) also depends on the possibility of setting a negative fixed wage.

${ }^{10}$ The number of firms is initially assumed to be exogenous.
} 
the owner of the firm who offers a contract in terms of quality of the product $q$ and wage $\omega$ to an employee (the agent).

The agents are wealth constrained with zero initial wealth and have a reservation wage of zero. They have quadratic effort costs, which are observable to the principal. The effort exerted determines the quality of the services. Thus, the products are also vertically differentiated. I normalize the quality $q$ in such a way that it linearly depends on the employees' effort. There is no asymmetric information between the principal and the agent. As quality is verifiable, the principals need not offer an incentive to the agents because they have all the necessary information to implement the efficient levels of quality.

I depart from the traditional Salop model by assuming that agents' utilities might positively depend on the well-being of the customers. The parameter $\theta$ measures the employees' customer orientation. There are two types of agents, the self-interested agents with $\underline{\theta}=0$ and the customer-oriented agents with $\bar{\theta}>0$, and their type is observable. ${ }^{11}$ Moreover, the number of agents of each type is larger than $n$. This means that there is perfect competition in the labour market. In this way, I have abstracted from potential problems concerning the firms' selection of employees with different degrees of customerorientation when they are in limited supply. This simplifying assumption allows me to focus on the impact of the presence of customer-oriented employees on firms' profits and on the customers' well-being, which is the main purpose of the article. ${ }^{12}$

After the employment decision, the firms offer imperfectly substitutable services, competing against each other on quality $q$ and prices $p$.

The timing of the model is as follows. In stage 1, each principal decides whether to hire a customer-oriented or a self-interested agent; In stage 2, each principal offers a contract in terms of the wage and the effort to his agent. Each agent accepts any contract which yields an expected utility of at least his reservation utility of 0 ; In stage 3, agents produce the good exerting the effort determined by the contract; finally, in stage 4, the customers choose from which firm to buy the good and profits are realized.

The principal can condition the wage on both quality and price. This is so as both factors may enter the agent's utility function. The quality enters the utility function both directly, as it affects the amount of effort the agent must exert, and indirectly, as it impacts on the customers' utility about which the agent may care. In contrast, price only affects the agent's utility function indirectly through its impact on the customers' well-being.

\footnotetext{
${ }^{11}$ In Section 6, I show that the main results are robust when this assumption is relaxed.

${ }^{12}$ The main results still hold when there is a limited supply of customer-oriented employees. This case is analyzed as a robustness check in Subsection 6.3.
} 


\subsection{The Objective Function}

Take a generic firm $i$. If a customer $k$ purchases one unit of the good from firm $i$, his utility is:

$$
U_{i k}=v\left(q_{i}\right)-p_{i}-t x_{i k},
$$

where $v\left(q_{i}\right)=\bar{v}+q_{i}$ represents the customer's benefit from the good offered by firm $i$. Customers derive a non-negative utility $\bar{v}$ from the good irrespective of its quality, i.e. $\bar{v} \geq 0$. The distance between firm $i$ and customer $k$ is denoted by $x_{i k}$. Customer $k$ incurs a "transportation cost", $t x_{i k}$, from traveling to firm $i$ and a cost of $t\left(\frac{1}{n}-x_{i k}\right)$ to the next firm $i+1$. The exogenous parameter $t$ represents the degree of horizontal differentiation of the goods offered by the firms. When $t$ is low, firms offer similar goods and competition is tough. A customer buys the good if he obtains a non-negative utility.

Being that Salop's is a model of localized competition, every firm competes only with the immediate neighbors. Each firm has only two competitors, those located to the right and left of it. Profits are given by the difference between revenues and the wage paid to the agent:

$$
\pi_{i}=p_{i} d_{i}-\omega_{i},
$$

where $p_{i}$ and $d_{i}$ are the price and the demand of firm $i$, respectively, and $\omega_{i}$ the wage paid to his agent.

The key assumption of this model is that employees may have pure altruistic preferences towards their customers. When this is the case, they are not only interested in providing high quality per se but care about the customers' well-being. ${ }^{13}$ Hence, they are also interested in the prices that are charged for the products. This assumption is particularly reasonable in the service sector whenever there is a strong interaction between the employees and the customers and this idea is advocated by psychologists and marketing scholars.

Applications of pure altruism are often found with smaller settings, such as the family environment where it is natural to think that an individual might care about the wellbeing of another member of his family (see Becker, 1974, 1981, and Cherchye et al., 2015). In larger contexts, it can plausibly be assumed that an individual cares about the average or total welfare of other individuals in the population (see Daube and Ulph, 2016). To simplify the math and for ease of exposition, in what follows I assume that employees care about the utility of the average customer buying the product from their firm. ${ }^{14}$

The agents' utility function consists of their own "egoistic" payoff, given by the difference between wage and effort costs, and their "customer orientation" payoff. Therefore, the utility of an agent who works in firm $i$ is given by:

$$
V_{i}=\omega_{i}-\frac{1}{2} q_{i}^{2}+\theta_{i} \bar{U}_{i}
$$

\footnotetext{
${ }^{13}$ This is in contrast with the case in which the employees only care about the quality (impure altruism) that is analyzed in Subsection 5.2.

${ }^{14}$ As a robustness check, the case in which the employees care about the overall utility of the customers buying the product from their firm is considered in Subsection 6.2.
} 
where $\bar{U}_{i}$ represents the weighted average utility of the customer buying a product from firm $i$. This utility is equal to: $\bar{U}_{i}=v\left(q_{i}\right)-p_{i}-\frac{t}{2}\left[\frac{\alpha_{1} x_{i l}+\alpha_{2} x_{i l^{\prime}}}{\left(\alpha_{1}+\alpha_{2}\right)}\right]$, with $\alpha_{1}+\alpha_{2}=1 ; \alpha_{1}$ and $\alpha_{2}$ are the normalized weights attached to the customers to the right and left of firm $i$, respectively, and coincide with their relative masses; $l$ (respectively $l^{\prime}$ ) is the customer located to the right (left) of firm $i$ who is indifferent between firm $i$ and firm $i+1$ (firm $i-1)$.

The model is solved under the assumption that the market is covered. In particular, the parameters are set in such a way that customers obtain a non-negative utility by buying the product irrespective of whether firms hire selfish or customer-oriented employees (see Assumption 1 in the appendix). Moreover, the values of the parameters are such that an interior solution is guaranteed. ${ }^{15}$ All the mathematical computations and proofs of the results are in the appendix.

\subsection{A Monopolistic firm}

As a benchmark case, I consider the equilibrium of a monopolistic firm.

Proposition 1. In equilibrium, a monopolistic firm always hires a customer-oriented agent.

If a monopolistic firm hires a customer-oriented agent, the quality of its product is higher relative to the case in which the agent is selfish. The higher quality allows the firm to charge a higher price and to increase demand for its product. Moreover, the agent's customer orientation reduces the agent's marginal cost of exerting an additional unit of effort. As a result, a customer-oriented agent receives a lower wage than a selfish agent. All these effects lead to higher profits and explain why the monopolistic firm always benefits from the presence of a customer-oriented agent.

The following lemma summarizes the impact of a change in the employee's customer orientation on quality, price, demand, wage, and profits of the monopolistic firm.

Lemma 1. The effects of an increase in the employee's customer orientation in monopoly are the following:

$$
\frac{\partial q}{\partial \bar{\theta}}>0 ; \quad \frac{\partial p}{\partial \bar{\theta}}>0 ; \quad \frac{\partial d}{\partial \bar{\theta}}>0 ; \quad \frac{\partial \omega}{\partial \bar{\theta}}<0 ; \quad \frac{\partial \Pi}{\partial \bar{\theta}}>0 .
$$

In the next section, I characterize the equilibrium in a competitive environment.

\footnotetext{
${ }^{15}$ The interval to which the parameters $\theta, t, n$ and $v$ must belong to are reported in Appendix A.
} 


\section{Competition and Employees' Customer Orienta- tion}

The equilibrium is determined by backward induction.

In the last stage of the game, customers choose from which firm to buy the good. A customer $l$ is indifferent between firm $i$ and $i+1$ if his utility from buying the product from firm $i, U_{i l}$, is equal to his utility from buying the product from firm $i+1, U_{i+1 l}$. Mathematically, this is the case when $U_{i l}=U_{i+1 l}$, or equivalently

$$
\bar{v}+q_{i}-p_{i}-t x_{i l}=\bar{v}+q_{i+1}-p_{i+1}-t\left(\frac{1}{n}-x_{i l}\right) .
$$

This implies that $x_{i l}=\frac{1}{2 n}+\frac{\left(q_{i}-q_{i+1}\right)+\left(p_{i+1}-p_{i}\right)}{2 t}$ and similarly $x_{i l^{\prime}}=\frac{1}{2 n}+\frac{\left(q_{i}-q_{i-1}\right)+\left(p_{i-1}-p_{i}\right)}{2 t}$. The demand for firm $i$ is given by $x_{i l}+x_{i l^{\prime}}$, that is:

$$
d_{i}=\frac{1}{n}+\frac{\left[2 q_{i}-q_{i+1}-q_{i-1}\right]+\left[p_{i+1}+p_{i-1}-2 p_{i}\right]}{2 t} .
$$

Knowing the demand, principal $i$ maximizes the following profits:

$$
\pi_{i}=p_{i}\left[\frac{1}{n}+\frac{\left[2 q_{i}-q_{i+1}-q_{i-1}\right]+\left[p_{i+1}+p_{i-1}-2 p_{i}\right]}{2 t}\right]-\omega_{i},
$$

subject to the employee's participation constraint:

$$
\omega_{i}-\frac{1}{2} q_{i}^{2}+\theta_{i} \bar{U}_{i}\left(q_{i}, p_{i}\right) \geq 0 .
$$

The firm's payoff when it employs a customer-oriented or a selfish agent is analyzed for any possible combination of types hired by the rival firms. This allows a comparison of the firms' profits and an analysis of the optimal choice of the agent in stage 1 . Let $\pi_{k l}^{j}$ denote the profit that firm $i$ obtains when it employs an agent of type $j$, and its direct rivals employ agents of type $k$ and $l$, where $j, k, l$ can be either customer-oriented $(M)$ or selfish $(S)$ individuals.

Proposition 2. The strategy of hiring a selfish agent is strictly dominated by the strategy of hiring a customer-oriented agent, i.e. $\pi_{k l}^{M}>\pi_{k l}^{S}$ for $k, l \in\{S, M\}$.

Regardless of whether the rival firms hire customer-oriented agents or not, principal $i$ is always better-off by hiring a customer-oriented agent. Suppose that all firms were employing self-interested agents. The generic firm $i$ would be willing to deviate by hiring a customer-oriented employee. By doing so, its quality would be higher than the quality provided by the rival firms. With higher quality, firm $i$ would obtain a comparative advantage in terms of demand and price, and, as a result, its profits would increase. But then, when one neighbour firm hires a customer-oriented employee, its competitors' best response is to follow suit. There is a "cascade effect" which leads to a unique Nash Equilibrium in which every firm hires a customer-oriented agent. Intuitively, an employer 
could pay a lower salary to a customer-oriented employee to implement the same qualityprice pair requested from a selfish employee.

The following lemma shows the solution of the subgame perfect equilibrium of the game in the presence of competition.

Lemma 2. There is a unique and symmetric subgame perfect equilibrium of the game in which each firm hires a customer-oriented employee, sets

$$
q_{M M}^{M}=\frac{1}{n}, \quad p_{M M}^{M}=t\left(\frac{1}{n}-\frac{3}{4} \bar{\theta}\right)
$$

and offers a wage which makes the employees' participation constraint bind, i.e.

$$
\omega_{M M}^{M}=\frac{1}{2 n^{2}}-\bar{\theta}\left[\bar{v}+\frac{1}{n}-\left(\frac{t}{n}-\frac{3}{4} t \bar{\theta}\right)-\frac{t}{4 n}\right] .
$$

Firms share the demand in the market $d_{M M}^{M}=\frac{1}{n}$ and profits are realized

$$
\pi_{M M}^{M}=\left(\frac{1}{n}\right)\left(\frac{t}{n}-\frac{3}{4} t \bar{\theta}\right)-\left[\frac{1}{2 n^{2}}-\bar{\theta}\left(\bar{v}+\frac{1}{n}-\left(\frac{t}{n}-\frac{3}{4} t \bar{\theta}\right)-\frac{t}{4 n}\right)\right] .
$$

As the above lemma shows, the employees' customer orientation affects neither quality nor demand, while it has a negative impact on the price charged by the firms. These results stand in stark contrast with those found under monopoly where quality, demand, and price increase in the employee's customer orientation (see Lemma 1). In contrast, wages are always decreasing in the customer orientation.

To provide an intuition, consider that a customer-oriented employee is willing to exert more effort if either he receives a higher wage or the customers' surplus is larger. Therefore, customer-orientation affects the quality-price pair chosen by the firms. But the direction of the effects depends on whether or not there is competition in the market.

When there is a monopoly, a higher customer orientation induces the firm to increase both quality and price. For each unit of the product which is sold, the firm is able to charge a higher price to reflect the higher product quality. Crucially, the increase in price is less than proportional to the increase in quality. As a result, the monopoly is able to attract new customers and enjoys an increase in the demand. Moreover, since the customers' surplus has increased, the relationship between customer orientation and wage is negative.

When there is competition, firms share the demand in the market. Since all firms follow the same strategy at the equilibrium, each firm's demand is constant and equal to $\frac{1}{n}$. As firms cannot win additional customers, they do not offer a higher quality product. However, a firm must charge a lower price to increase the customers' surplus and pay its customer-oriented employee a lower wage. Because the other firms do exactly the same, this price reduction negatively impacts on revenues. If a firm deviated by not reducing the price, its profits would decrease since part of its demand would be stolen by its rivals. Notice that at the equilibrium the firms prefer to reduce price maintaining quality constant, instead of increasing quality keeping the price constant, because providing more quality is more expensive as it requires more effort. 


\section{A Prisoners' Dilemma}

The previous section shows that hiring a customer-oriented agent is a dominant strategy for each firm. But do firms benefit from hiring a customer-oriented agent? The answer is provided by the next proposition.

Proposition 3. All firms would obtain higher profits if they colluded to hiring selfinterested rather than customer-oriented agents, i.e. $\pi_{S S}^{S}>\pi_{M M}^{M}$, whenever $t>\hat{t}=$ $\frac{4(n \bar{v}+1)}{8-3 n \bar{\theta}}$.

For $t$ sufficiently high, all firms would be better off hiring self-interested agents. They would like to coordinate and hire selfish individuals but they cannot. As I have shown in the previous section, the strategy of hiring self-interested agents is strictly dominated by that of hiring customer-oriented agents. Hence, the very presence of a customer-oriented workforce can hurt firms. ${ }^{16}$

To understand the reason why the prisoners' dilemma may arise, it is useful to study the effect of the different parameters on the firms' profits more in detail. Consider that when all firms hire self-interested agents, profits are:

$$
\pi_{S S}^{S}=\left(\frac{1}{n}\right)\left(\frac{t}{n}\right)-\frac{1}{2 n^{2}}=\frac{2 t-1}{2 n^{2}}
$$

and, when all firms hire customer-oriented agents, profits are:

$$
\pi_{M M}^{M}=\left(\frac{1}{n}\right)\left(\frac{t}{n}-\frac{3}{4} t \bar{\theta}\right)-\left[\frac{1}{2 n^{2}}-\bar{\theta}\left(\bar{v}+\frac{1}{n}-\frac{5}{4} \frac{t}{n}+\frac{3}{4} t \bar{\theta}\right)\right]
$$

Impact of Employees' Customer Orientation. The employees' customer orientation has a countervailing effect on profits. On the one hand, profits increase due to a reduction in the wage:

$$
\omega_{M M}^{M}=\frac{1}{2 n^{2}}-\bar{\theta}\left(\bar{v}+\frac{1}{n}-\frac{5}{4} \frac{t}{n}+\frac{3}{4} t \bar{\theta}\right)<\frac{1}{2 n^{2}}=\omega_{S S}^{S}
$$

Customer-oriented employees derive non-material benefits from providing high-quality goods to customers. Therefore, they provide a given level of quality for a lower wage compared to self-interested agents. The higher the employees' customer orientation, the lower the wage they receive, i.e. $\frac{\partial \omega_{M M}^{M}}{\partial \bar{\theta}}<0$. This effect is in line with the literature on psychological incentives and it would be obtained also if employees were just interested in quality.

\footnotetext{
${ }^{16}$ One might wonder if repeated interaction among firms could sustain an equilibrium in which each firm hires a selfish agent. However, this would require playing the entire stage game in every period. As a result, the hiring decision should be taken every time. This is in contrast with real-world employment contracts whose duration is typically long.
} 
The employees' customer orientation also has a negative impact on profits, though. This is due to a reduction in the price charged by the firms (rent reduction effect):

$$
p_{M M}^{M}=\frac{t}{n}-\frac{3}{4} t \bar{\theta}<\frac{t}{n}=p_{S S}^{S}
$$

The price has a negative impact on the customers' well-being and indirectly it negatively impacts on the employees' utility. For this reason, firms do not charge the same price as when agents are selfish, thereby extracting less customers' surplus. Notice that, to satisfy the employees' participation constraint, firms prefer to reduce price maintaining quality constant because providing more quality is more expensive as it requires more effort. Indeed, firms decide to set the same level of quality in the two scenarios, i.e. $q_{M M}^{M}=q_{S S}^{S}$. At the same time, since all firms are symmetric and follow the same hiring strategy, they do not steal market shares from their rivals. This means that firms do not attract additional customers by offering a lower price. Therefore, the demand does not change, i.e. $d_{M M}^{M}=d_{S S}^{S}=\frac{1}{n}$.

When the negative effect on profits due to the reduction in the price dominates the positive effect due to the reduction in the wage, firms would obtain higher profits by hiring selfish rather than customer-oriented employees. All else being equal, this is more likely to be the case when the employees' customer orientation is lower. To see this, consider that an increase in $\bar{\theta}$ has a linear negative impact on the price, while it has an increasingly negative impact on the wage, i.e. $\frac{\partial^{2} p_{M M}^{M}}{\partial \bar{\theta}^{2}}=0$ and $\frac{\partial^{2} \omega_{M I M}^{M}}{\partial \bar{\theta}^{2}}>0$. There is a threshold value of $\bar{\theta}$ below which the negative effect on the price dominates the negative effect on the wage.

To provide an intuition suppose that $\bar{\theta}$ takes a higher value. Firms can now pay a lower wage to customer-oriented employees even for the initial price-quality pair because the customers' utility is positive. Because of competitive pressure, firms are forced to reduce prices. Even though firms do not attract additional customers by reducing their price, they do increase the customers' surplus, and can further decrease the employees' wage. The customer-oriented employee is indeed willing to accept a lower salary in exchange for a greater customer surplus. The more motivated the agent is, the lower the price that the firm charges to its customers and, in turn, the larger the customers' surplus. When $\bar{\theta}$ is small, customers' surplus is small too, and the effect on profits of the price reduction outweighs that of the wage reduction. In contrast, when $\bar{\theta}$ is large, customers' surplus is already high. This implies that even if the firms did not charge a lower price, the salary would drop substantially. When this is the case, the benefit stemming from the wage reduction more than offsets the cost due to the lower profit margin.

Let us now consider the market parameters. Proposition 3 shows that the prisoners' dilemma is more likely to occur when the market is more concentrated ( $t$ is high and/or $n$ is low), and when the customers have a low valuation of the product ( $\bar{v}$ is low). In what follows, I explain the impact of each market parameter on the profits more in detail. 


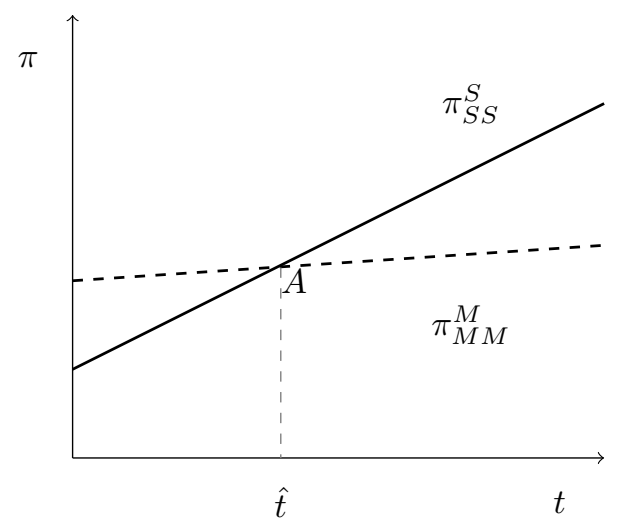

(a)

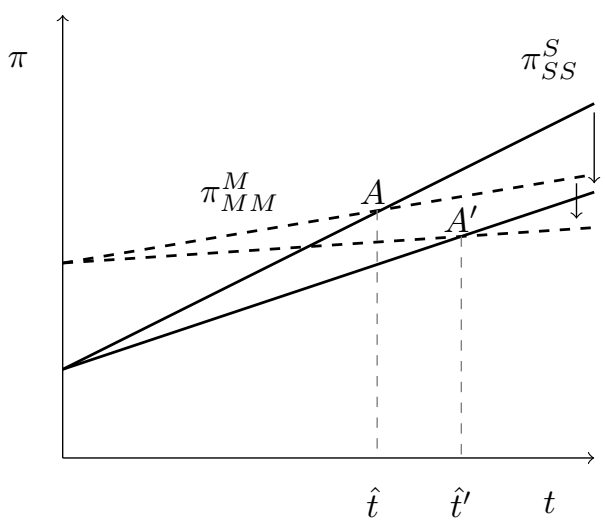

(b)

Figure 1: Comparison between profits as a function of $t$

Impact of Horizontal Differentiation. Figure 1(a) illustrates firms' profits as a function of $t$ when all firms hire customer-oriented agents (dashed line) and when all of them would have hired selfish individuals (solid line). It is important to notice that the dashed line is flatter than the solid line. To better understand why this occurs, consider the derivative of the differential profits between $\pi_{S S}^{S}$ and $\pi_{M M}^{M}$ with respect to $t$ :

$$
\frac{\partial\left(\pi_{S S}^{* S}-\pi_{M M}^{* M}\right)}{\partial t}=\frac{\bar{\theta}(8-3 n \bar{\theta})}{4 n}>0
$$

The degree of differentiation of the products $t$ positively impacts on profits irrespective of whether the agents are customer-oriented or not. As $t$ takes a higher value, there is less competition because the products are less substitutable and, as a result, firms can charge higher prices. However, the positive impact of $t$ on profits is higher when agents are self-interested. This result depends on two effects, one on the price of the good and one on wages, that go in the same direction.

First, with customer-oriented employees firms cannot increase the price as much as in the case in which employees are selfish. This is because a higher price negatively affects customers' utility and, through this channel, the employees' utility. Second, $t$ has no impact on the wages paid to selfish agents, but it impacts positively on the wages paid to customer-oriented employees. In addition to the negative effect due to the resulting higher price, a higher $t$ directly affects the customers' utility too by making them bear a higher transport cost. These effects will, in turn, indirectly impact on the utility of customer-oriented employees, and principals will need to compensate them with higher salaries so as to satisfy their participation constraints. Hence, the different slopes of the profits lines in Figure 1.

Impact of the Number of Firms. A higher number of firms in the market reduces firms' profits irrespective of whether the agents are customer-oriented or not: both the solid and the dashed lines tilt down (see the second graph in Figure 1). However, the 
negative impact of the number of firms on the profits is higher when the agents are selfish. Consider the derivative of the differential profits with respect to $n$ :

$$
\frac{\partial\left(\pi_{S S}^{S}-\pi_{M M}^{M}\right)}{\partial n}=-\frac{\bar{\theta}(2 t-1)}{n^{2}}<0
$$

The above inequality implies that the prisoners' dilemma occurs for a higher value of $t$ when the number of firms in the market increases.

To better understand this result, consider that an increase in $n$ has a negative impact on quality but it reduces the distance between customers and firms, leading to a countervailing effect on the customers' well-being. Which effect dominates depends on the degree of differentiation of the products/services. When $t$ is high, namely when firms offer highly differentiated services, customers are less interested in quality than in the transport cost. Therefore, they choose a product closer to their location. When this is the case, an increase in the number of firms $n$ has a positive impact on the customers' utility. This effect has an indirect positive impact on the employees' utility allowing the firm to pay a lower wage and to increase profits by hiring a customer-oriented employee. This makes the prisoners' dilemma less likely to arise.

Impact of Customers' Valuation. An increase in $\bar{v}$ has a positive impact on firms' profits when agents are customer-oriented. This is because an increase in $\bar{v}$ has a positive impact on the customers' utility. When customers value more the service offered by the firms, their utility increases and indirectly this positively impacts on the utility of a customer-oriented employee. When this is the case, principals can pay this type of employees a lower wage, leading to an increase in profits. In contrast, since the market is covered, the customer's valuation $\bar{v}$ has no impact on the firms' profits if agents are self-interested. Consider the derivative of the differential profits with respect to $\bar{v}$ :

$$
\frac{\partial\left(\pi_{S S}^{S}-\pi_{M M}^{M}\right)}{\partial \bar{v}}=-\bar{\theta}<0
$$

As $\bar{v}$ increases, the loss obtained by hiring customer-oriented agents is reduced, when $t$ is sufficiently high.

Overall, the prisoners' dilemma is more likely to arise when the degree of differentiation of the products $t$ is high, and when the agents' customer orientation $\bar{\theta}$, the number of firms $n$, and the customer's valuation $\bar{v}$ are low. Therefore, when the market is more concentrated, firms would be better off by hiring selfish agents.

\subsection{Impact of Parameters on the Customers' Utility}

The average customer's utility derived from buying a product from firm $i$ when all agents are selfish and when all agents are customer-oriented are equal to the following terms, respectively:

$$
\bar{U}_{S S}^{S}=\bar{v}+\frac{1}{n}-\frac{5}{4} \frac{t}{n} ; \quad \bar{U}_{M M}^{M}=\bar{U}_{S S}^{S}+\frac{3}{4} t \bar{\theta} .
$$


The degree of product differentiation $t$ has a negative impact on the customer's utility irrespective of whether the agents are self-interested or not. As $t$ takes a higher value, products are more horizontally differentiated. This reduces competition in the market and increases equilibrium prices. However, the prices paid by the customers when the agents are customer-oriented are lower than the ones they would pay if they were selfish. In other words, the negative impact of $t$ is higher when agents are self-interested. This is a direct consequence of the effects explored in the previous section.

The number of firms $n$ has a positive impact on the customer's utility if $t>\frac{4}{5}$. As shown before, an increase in the number of firms reduces the distance between customers and firms and this leads to an increase in their utility. In contrast, if competition is more severe, i.e. $t<\frac{4}{5}$, customers are more interested in the quality provided by each firm than in the transport cost. Since an increase in the number of firms has a negative impact on quality, this leads to a reduction in the customers' utility.

The impact of the employees' customer orientation on the customers' welfare is unambiguously positive when the number of firms is exogenous. This impact is positive because $\bar{\theta}$ increases competition reducing the price charged by the firms. However, when the number of firms is endogenous, there will be an additional effect that goes in the opposite direction.

When the assumption of an exogenous number of firms is relaxed, there is an additional stage, stage 0 , in which each firm must decide whether to enter the market and incur an entry $\operatorname{cost} F \geq 0$, or stay out. The entry cost $F$ affects the degree of competition among firms and through this channel the customers' utility. The equilibrium number of firms competing in the market is determined by the zero-profit condition. ${ }^{17}$

When the prisoner's dilemma occurs ( $t$ is high), the gross profits obtained by hiring self-interested agents would be higher than those obtained by hiring customer-oriented agents, and so would be the number of firms. Because of horizontal differentiation when $t>\frac{4}{5}$ a wider variety of goods is beneficial to customers. Therefore, customer orientation has a negative effect on the customers' utility due to a reduction in the number of firms. Whether this negative effect dominates the positive effect on the customers' utility due to the price reduction depends on the values of the parameters. In particular, when $t$ is sufficiently high and the agent's customer orientation $\bar{\theta}$ is sufficiently low, the former effect is higher than the latter.

Remark 1. When the number of firms is endogenous, the positive impact of the agents' customer orientation on the customers' utility may be mitigated or become negative.

\subsection{Customer-Oriented versus Quality-Oriented Employees}

The main results of the paper crucially depend on the assumption that motivated employees are interested in the customers' well-being. When employees are customer-oriented,

\footnotetext{
${ }^{17}$ Markets with lower entry costs $F$ are more competitive because the number of firms in the market is larger and therefore prices lower. Remember that firms are equally distributed on the Salop's circle.
} 
they also care about the price charged by the firms. As I have highlighted before, in a competitive environment firms will strategically reduce their price. The magnitude of this price reduction depends on the employees' customer orientation and can be large enough to outweigh the gain generated by lower wages.

In this section I highlight how the results dramatically change when the motivated employees only care about the quality of the service provided. The utility of a qualityoriented employee who works in firm $i$ is:

$$
\hat{V}_{i}=\omega_{i}-\frac{1}{2} q_{i}^{2}+\bar{\theta} q_{i}
$$

I use the notation $\hat{V}_{i}$ to distinguish quality-oriented employees from customer-oriented employees.

Lemma 3. There is a unique and symmetric subgame perfect equilibrium of the game in which each firm hires a quality-oriented employee, sets

$$
\hat{q}_{M M}^{M}=\frac{1}{n}+\bar{\theta}, \quad \hat{p}_{M M}^{M}=\frac{t}{n},
$$

and offers a wage which makes the employees' participation constraint bind, i.e.

$$
\hat{\omega}_{M M}^{M}=\frac{1}{2 n^{2}}-\frac{\bar{\theta}^{2}}{2} .
$$

Firms share the demand in the market $\hat{d}_{M M}^{M}=\frac{1}{n}$ and profits are realized

$$
\hat{\pi}_{M M}^{M}=\frac{2 t-1}{2 n^{2}}+\frac{\bar{\theta}^{2}}{2} .
$$

As the above lemma shows, the employees' quality-orientation does not affect prices, while it has a positive impact on quality. Intuitively, if motivated employees are merely interested in quality, the strategic effect on the price disappears. Moreover, since the agent's marginal cost of eliciting higher effort is reduced, quality-oriented employees provide goods of a higher quality for a lower wage. ${ }^{18}$ As a result, the employees' quality-orientation increases profits. The next proposition illustrates this result.

Proposition 4. Firms are always better off hiring quality-oriented employees.

Therefore, this seemingly negligible difference in the specification of the utility function leads to dramatically different conclusions concerning the desirability of hiring a motivated workforce.

This distinction between customer-oriented and quality-oriented employees can be attributed to the difference between pure and impure altruism. While pure altruistic agents care about the well-being of others, impure altruistic agents directly benefit from

\footnotetext{
${ }^{18}$ Notice that with quality-oriented employees the firm's cost, i.e. the salary, cannot be reduced by lowering the price charged to the customers.
} 
their actions. In my model, customer-oriented employees displays pure altruism because they care about the customers' utility. This stands in contrast with the case in which motivated employees derive utility from the quality of the good they provide. Since quality linearly depends on the effort exerted by the employees, this case leads to the notion of impure altruism (see Delfgaauw and Dur, 2007, 2008).

Since the main results of the paper crucially depend on the employees' interest in the customers' well-being rather than just in the quality of the good or service provided, the analysis calls for additional empirical studies. To test my model one would need to collect evidence on which preference specification is empirically the most plausible and check if it depends on the sector/industry considered. The first step would be to determine whether employees derive non-egoistic benefits from providing some types of services. If this were the case, the second step would be to determine whether employees are interested in the customers' well-being or in the quality per se. This would require the use of survey data and the development of a measure of workers' orientation towards customers. Then, one could determine which type of employees firms hire and if their hiring decisions depend on the industry and/or the degree of competition.

\section{Robustness Checks}

In this section, I show that the main results of the paper are robust to relaxing some of the assumptions of the baseline model. In particular, I analyze the case in which principals do not have information about the employees' customer orientation (Subsection 6.1). Then, I go on to consider an alternative specification of the employees' customer orientation (Subsection 6.2). More specifically, customer-oriented employees might be interested in the total customers' surplus buying the product from their firm. In Subsection 6.3, I study the case in which there is limited supply of customer-oriented agents. Finally, in

Subsection 6.4, I consider the case in which each firm also incurs a material cost $c$ per unit of production.

In each of the following subsections, I illustrate how the different assumptions affect the main results of the paper and provide some intuitions, while I relegate all the computations and proofs of the results to Appendix B.

\subsection{Asymmetric information on $\theta$}

It is not always straightforward to identify customer-oriented employees and recruit them. It is plausible to assume that principals do not have perfect information on the agents' types they face. Here, I consider the case in which the employees have private information about their own customer orientation.

The timing of the baseline model shown in Section 3 is enriched with stage 0, wherein each agent is privately informed about his own customer orientation. 
To attain separation of types, principals can follow two alternative strategies (see Chapter 2 in Laffont and Martimort, 2001). One is to offer different contracts for different types of agents, another is to only hire customer-oriented employees by offering only one contract that selfish employees would not accept. In the former case, the principals would pay an information rent to customer-oriented agents in order to attain separation of types. ${ }^{19}$ In the latter, only the participation constraint of customer-oriented employees bind and no information rent is given up to them. ${ }^{20}$

Remark 2. Under asymmetric information, all firms hire customer-oriented employees. For $t$ sufficiently high, firms would be better off hiring self-interested agents.

Principals are better off offering a contract just to customer-oriented agents. By doing so, they are able to offer customer-oriented agents the same contract obtained in the firstbest. This contract will not be accepted by selfish agents and principals do not have to pay an information rent to the customer-oriented agents. Since the solution is substantially unaltered as compared to when there is no private information about the employees' customer orientation, for certain values of the parameters, the prisoners' dilemma arises.

\subsection{Alternative Specification of the Employees' Customer Ori- entation}

In the baseline model, I have assumed that a customer-oriented employee who works in firm $i$ cares about the utility of the average customer who buys the product from firm $i$. However, this is not the only way to model the preferences of a customer-oriented employee.

As a robustness check, I now study the case in which a customer-oriented agent who works in firm $i$ cares about the overall surplus of the customers who buy the product from firm $i$.

Let $C S_{i}$ be the sum of the customers' surplus buying the product from firm $i$ :

$$
C S_{i} \equiv \int_{0}^{x_{i l}}\left[\left(\bar{v}+q_{i}-p_{i}\right)-t x\right] d x+\int_{0}^{x_{i l^{\prime}}}\left[\left(\bar{v}+q_{i}-p_{i}\right)-t x\right] d x
$$

In the above expression $x_{i l}$ is the mass of customers on the left of firm $i$ and $x_{i l^{\prime}}$ is the mass of customers on its right.

The utility of an agent who works in firm $i$ is now given by:

$$
\tilde{V}_{i}=\omega_{i}-\frac{1}{2} q_{i}^{2}+\theta_{i} C S_{i}
$$

I use the notation $\tilde{V}_{i}$ to distinguish this case from the baseline specification.

\footnotetext{
${ }^{19}$ In this case, the $\bar{\theta}$-agents would benefit from an information rent stemming from their ability to possibly mimic the selfish agents. For the $\bar{\theta}$-agents the incentive constraints are binding, whereas for the $\underline{\theta}$-agents the participation constraints bind.

${ }^{20}$ The selfish agents never choose the contract targeted for the $\bar{\theta}$-agents because they would obtain a negative utility.
} 
Remark 3. Under this alternative specification of the employees' customer orientation, firms always hire customer-oriented employees, but they would be better off hiring selfish employees.

Even with this different specification of customer orientation, there is a unique and symmetric subgame perfect equilibrium in which each firm hires a customer-oriented employee. That is, the strategy of hiring a selfish agent is strictly dominated by the strategy of hiring a customer-oriented employee. Intuitively, an employer could pay a lower salary to a customer-oriented employee to implement the same quality-price pair requested from a selfish employee.

However, even if hiring a customer-oriented employee is a dominant strategy, I find that all firms would obtain higher profits if they colluded to hiring selfish employees. The employees' customer orientation impacts on the price, quality, demand, wage and profits in a similar way irrespective of whether the employees care about the well-being of the average customer or that of all customers. In particular, the employees' customerorientation has no impact on quality and demand, but it has a negative impact on prices and wages. Therefore, qualitatively the results continue to be the same. Moreover, in this case, the negative impact on the prices always outweighs the negative impact on the wages. Namely, with this alternative specification of the employees' customer orientation, the results are even stronger as firms are always trapped in a prisoners' dilemma. This is because under this alternative specification employees weigh the customers' utility less and principals have to pay them a higher wage. In particular, now the utility of customeroriented employees depends on the mass of customers who are served by their firm. This mass is negatively affected by the number of firms in the market. In particular, the weigh attached to this payoff is $\frac{1}{n}$. In contrast, in the baseline model the "customer-orientation" payoff does not depend on the number of customers who are served and so its weight is 1 .

To conclude, depending on the type of customer-oriented preferences, the curse of hiring customer-oriented employees is more or less magnified. The baseline specification highlights how the market conditions affect the likelihood that the prisoners' dilemma arises.

\subsection{Limited Supply of Customer-Oriented Employees}

One important assumption of the model is that there is a sufficient supply of customeroriented employees. In this way, I have abstracted away from potential problems concerning the firms' selection of employees with different degrees of customer orientation when they are in limited supply. This simplifying assumption has allowed me to better focus on the impact of the presence of customer-oriented employees on firms' profits and customers' satisfaction, which is the main purpose of this article.

In this subsection, I relax this assumption considering what happens when customeroriented employees are scarce. If there is a limited supply of customer-oriented employees, an employee's outside option will depend on the offer he receives from the other firms in 
the market. Following Englmaier and Leider (2012), I model the bargaining occurring between firms and employees. In particular, I assume that firms alternate their offers to the employees, and each employee accepts the contract if it is superior to his current offer. The firms stop when each employee accepts the contract.

When there are few customer-oriented employees in the market, firms obtain higher profits by hiring customer-oriented rather than selfish agents. Suppose there is just one customer-oriented agent who is hired by firm $i$. The quality provided by firm $i$ is higher than the quality provided by the competitors. A higher quality leads to a higher demand and a higher price. ${ }^{21}$

As the firm that hires the customer-oriented agent obtains a comparative advantage in terms of quality, demand and price, with respect to the rival firms, firm $i$ has to offer a contract that provides a sufficiently large rent to the customer-oriented agent so as to prevent a counter-offer from the other firms. Of course, this additional rent is costly to firm $i$ and coincides with the difference in the profits obtained by hiring the customeroriented rather than the selfish agent. Firm $i$ offers the customer-oriented agent a higher wage than the one received by selfish agents up to the point at which all firms will be indifferent between hiring customer-oriented or selfish employees. As a result, the final contract will be perceived as "neutral".

Remark 4. With limited supply of customer-oriented agents, firms would be better off if all of them hired selfish agents.

The profits obtained by firms when all of them decide to hire selfish employees are always greater than the ones obtained when just one firm hires the customer-oriented agent.

The limited supply of customer-oriented agents may explain why we often observe that firms operating in the same sector behave in a different way concerning their choices of wages, qualities, and prices.

\subsection{Different Production Technology}

For ease of exposition, in the baseline model the cost of production of the good only consists of the employee's wage $(\omega)$. In other words, I have so far assumed that the marginal cost of producing the good is equal to 0 . More realistically, firms bear costs other than the salary of their manager and these may depend on the amount of production. In this subsection, I analyze the model assuming that each firm incurs a material cost $c$ per unit of production, like in the standard Salop model. Since the unit cost is going to impact on the price charged by the firms, the condition for which the market is covered must be adapted. ${ }^{22}$

\footnotetext{
${ }^{21}$ This result is similar to the one obtained under monopoly.

${ }^{22}$ In particular, the condition is satisfied and all customers buy a unit of the good/service when $t \leq$ $\frac{2}{3}(\bar{v} n+1-c)$.
} 
The profit of firm $i$ is:

$$
\pi_{i}=\left(p_{i}-c\right) d_{i}-\omega_{i}
$$

When this is the case, there is a unique and symmetric subgame perfect equilibrium of the game in which each firm hires a customer-oriented employee, sets

$$
q_{M M}^{M}=\frac{1}{n}, \quad p_{M M}^{M}=t\left(\frac{1}{n}-\frac{3}{4} \bar{\theta}\right)+c,
$$

and offers a wage which makes the employee's participation constraint bind, i.e.

$$
\omega_{M M}^{M}=\frac{1}{2 n^{2}}-\bar{\theta}\left[\bar{v}+\frac{1}{n}-\left(\frac{t}{n}-\frac{3}{4} t \bar{\theta}\right)-c-\frac{t}{4 n}\right] .
$$

Firms share the demand in the market $d_{M M}^{M}=\frac{1}{n}$ and profits are realized

$$
\pi_{M M}^{M}=\left(\frac{1}{n}\right)\left(\frac{t}{n}-\frac{3}{4} t \bar{\theta}\right)-\left[\frac{1}{2 n^{2}}-\bar{\theta}\left(\bar{v}+\frac{1}{n}-\left(\frac{t}{n}-\frac{3}{4} t \bar{\theta}\right)-c-\frac{t}{4 n}\right)\right] .
$$

It is simple to compare these results with those obtained in Lemma 2. In particular, quality and demand are not affected by $c$, whereas firms charge a higher price as $c$ increases. This effect has a negative impact on the customers' surplus and, as a result, firms have to compensate customer-oriented employees with a higher wage to satisfy their participation constraints. Finally, the higher wage impacts negatively on firms' profits.

Remark 5. All firms would obtain higher profits if they colluded to hiring self-interested rather than customer-oriented agents whenever $t>\hat{t}=\frac{4(n \bar{v}+1-n c)}{8-3 n \bar{\theta}}$.

The strategy of hiring a customer-oriented employee continues to be the dominant one. I find that the prisoners' dilemma is more likely to arise as $c$ increases. As $c$ takes higher values, customers' surplus shrinks and customer-oriented employees receive a higher wage. This leads to a reduction in firms' profits. In contrast, $c$ would not impact on the wage paid to selfish employees. Moreover, the effect of $c$ on the price is the same irrespective of whether firms hire selfish or customer-oriented employees. The main result of the paper still holds and it is even stronger. Introducing a material cost of production $c$ in the analysis increases the likelihood of having the prisoners' dilemma. However, it must be noticed that $c$ reduces the interval of the parameters under which the market is covered.

\section{Concluding Remarks}

In this paper I have modeled an employee as "customer oriented" when he is interested in the customers' well-being. While the marketing literature has stressed how firms can benefit from hiring this type of motivated employees, I have shown that this may not be true in a competitive environment. Employees' customer orientation has a countervailing effect on firms' profits. A higher customer orientation has a negative effect on the price 
of the product offered by the firms and, as a result, it impacts negatively on profits. However, customer-oriented employees receive a lower wage than selfish employees and this positively impacts on profits. Which effect dominates depends on the degree of differentiation of the products offered by the firms, on the number of firms, and on the degree of customer orientation. When the negative effect on profits due to the reduction in the price dominates the positive effect due to the reduction in the wage, firms would obtain higher profits by hiring selfish rather than customer-oriented employees. However, firms are trapped in a prisoners' dilemma as the strategy of hiring self-interested agents is dominated by the strategy of hiring customer-oriented agents. Hence, the very presence of customer-oriented agents may hurt firms. ${ }^{23}$

One testable implication of the paper is that we should observe that in more concentrated markets the strength of the relationship between the employees' customer orientation and the firms' profits is mitigated. Concerning the service sector, some articles in the marketing literature provide some empirical evidence which is consistent with this prediction. These articles find that the relationship between the employees' customer-orientation and the firms' profits depends on the intensity of competition and their arguments are in line with the results found in my article. ${ }^{24}$

The results found under competition stand in stark contrast with those obtained under monopoly. When there is only one firm in the market, this firm always benefits from hiring a customer-oriented employee. A higher customer orientation induces the firm to increase both quality and price. For each unit of the product which is sold, the firm is able to charge a higher price to accompany the increase in product quality. Crucially, the monopoly is also able to attract new customers and enjoys an increase in the demand. Moreover, since the customers' surplus has increased, the relationship between customer orientation and wage is negative.

The model is solved under the crucial assumption that the market is covered. If the market were not covered, the degree of differentiation of the products would be so high that firms could act as monopolists with the potential customers who are located near them. In other words, each firm would be located so far away from its rivals that it would not actually compete with them. If this were the case, the analysis and the results would be very similar to those obtained under monopoly: by hiring a customer-oriented employee a firm could increase its demand and enjoy higher profits. As a result, firms would not be hurt by the presence of customer-oriented employees.

Another crucial assumption is that motivated employees exhibit pure altruism, i.e.

\footnotetext{
${ }^{23}$ Caring about customers does not always guarantee profitability as can be observed in the US airline industry (see the case of Virgin America as reported in the article of The New York Times on September 7, 2013. The article raises the question: "can an airline make money and still be beloved?").

${ }^{24}$ Kohli and Jaworski (1990) and Day and Wensley (1988) argue that when competition is weak, employees' customer orientation does not play an important role in the customers' choice because customers are stuck with the organizations' products and services. By contrast, they suggest that when competition is fierce, customers have many alternative options. In this case, employees' customer orientation plays a key role in satisfying the customers' needs and it is a key determinant of firms' performance.
} 
they care about the customers' well-being. This stands in contrast with impure altruism which would lead to a model where motivated employees derive utility from the quality of the good they provide. If motivated employees were merely interested in quality, the strategic effect on the price would not arise and firms would not be hurt by the presence of motivated employees. It must be said that the existing experimental evidence mostly supports the assumption of impure altruism. However, there is also a body of literature that finds evidence that individuals exhibit pure altruistic preferences.

For future research, it would be important to understand whether motivation (in the form of customer orientation) can be crowded in or out by actions that the principal can take (see Frey et al., 1997, Benabou and Tirole, 2003, and Akerlof and Kranton, 2005) and how the presence of motivated agents affects the organizational form of the firms. In this regard, Ghatak and Mueller (2011) stress the importance of understanding the firms' organizational choice between for-profits and not-for-profits in a (labor) market setting. Moreover, it is natural to think of motivated workers in the public service provision, such as health care and education sectors (see for example Francois, 2000, and Delfgaauw and Dur, 2008). ${ }^{25}$ When the analysis focuses on these sectors, it is important to take into account that in many countries these services are provided by both public and private institutions. Since in numerous markets for-profit firms compete with cooperative firms and non-profit organizations, there is a growing literature on mixed oligopoly (see for example CasadesusMasanell and Ghemawat, 2006, and Marini et al., 2015). ${ }^{26}$ Considering a mixed oligopoly environment, in Manna (2016) I study the interaction between public and private firms and analyze how the presence of customer-oriented employees impacts on the firms' profits and social welfare.

Finally, the analysis of the impact of different forms of employees' motivation on the customers' satisfaction and on the firms' profits can be extremely useful for firms in the selection of the right applicant for a specific job. Firms make increasingly use of personality tests to hire employees for positions across many levels in an organization. ${ }^{27}$ This practice may allow firms to have a better understanding of the preferences of the potential candidates for a job position (see Englmaier et al., 2016).

\footnotetext{
${ }^{25}$ Indeed, the empirical evidence has documented the presence of motivated employees in the health care sector showing that job satisfaction crucially depends on both monetary and non-monetary aspects of employment (see Shields and Ward, 2001, Antonazzo et al., 2003, Ikenwilo and Scott, 2007, and Leonard and Masatu, 2010).

${ }^{26} \mathrm{~A}$ mixed oligopoly is in general defined as a market in which two or more firms with different objective functions co-exist (see for a survey Fraja and Delbono, 1990, and Nett, 1993.)

${ }^{27}$ In $200126 \%$ of large U.S. employers used pre-hire assessments and by 2013 the number had climbed to $57 \%$ (see the article of the Wall Street Journal on April 14, 2015: "today's personality tests raise the bar for job seekers").
} 


\section{References}

Akerlof, G. A., Kranton, R. E., 2005. Identity and the economics of organizations. Journal of Economic perspectives, 9-32.

Andreoni, J., 1989. Giving with impure altruism: Applications to charity and ricardian equivalence. The Journal of Political Economy, 1447-1458.

Andreoni, J., 1990. Impure altruism and donations to public goods: A theory of warmglow giving. The economic journal 100 (401), 464-477.

Andreoni, J., Miller, J., 2002. Giving according to garp: An experimental test of the consistency of preferences for altruism. Econometrica 70 (2), 737-753.

Antonazzo, E., Scott, A., Skatun, D., Elliott, R., et al., 2003. The labour market for nursing: a review of the labour supply literature. Health economics 12 (6), 465-478.

Baggs, J., De Bettignies, J.-E., 2007. Product market competition and agency costs. The Journal of Industrial Economics 55 (2), 289-323.

Becker, G. S., 1974. A theory of social interactions. Journal of Political Economy 82 (6), 1063-1093.

Becker, G. S., 1981. Altruism in the family and selfishness in the market place. Economica 48 (189), 1-15.

Benabou, R., Tirole, J., 2003. Intrinsic and extrinsic motivation. The Review of Economic Studies 70 (3), 489-520.

Benabou, R., Tirole, J., 2006. Incentives and prosocial behavior. The American Economic Review 96 (5), 1652-1678.

Besley, T., Ghatak, M., 2005. Competition and incentives with motivated agents. The American Economic Review 95 (3), 616-636.

Biglaiser, G., Ma, A. C.-t., 2007. Moonlighting: public service and private practice. The RAND Journal of Economics 38 (4), 1113-1133.

Bond, P., Glode, V., 2011. Bankers and regulators.

Bove, L. L., Johnson, L. W., 2000. A customer-service worker relationship model. International Journal of Service Industry Management 11 (5), 491-511.

Buurman, M., Delfgaauw, J., Dur, R., Van den Bossche, S., 2012. Public sector employees: Risk averse and altruistic? Journal of Economic Behavior \& Organization 83 (3), 279291. 
Casadesus-Masanell, R., Ghemawat, P., 2006. Dynamic mixed duopoly: A model motivated by linux vs. windows. Management Science 52 (7), 1072-1084.

Charness, G., Cobo-Reyes, R., Sánchez, Á., 2016. The effect of charitable giving on workers' performance: Experimental evidence. Journal of Economic Behavior \& Organization 131, 61-74.

Cherchye, L., Cosaert, S., Demuynck, T., De Rock, B., 2015. Noncooperative household consumption with caring. Available at SSRN 2694972.

Daube, M., Ulph, D., 2016. Moral behaviour, altruism and environmental policy. Environmental and Resource Economics 63 (2), 505-522.

Day, G. S., Wensley, R., 1988. Assessing advantage: a framework for diagnosing competitive superiority. The Journal of Marketing, 1-20.

Delfgaauw, J., Dur, R., 2007. Signaling and screening of workers' motivation. Journal of Economic Behavior \& Organization 62 (4), 605-624.

Delfgaauw, J., Dur, R., 2008. Incentives and workers' motivation in the public sector. The Economic Journal 118 (525), 171-191.

Donavan, D. T., Brown, T. J., Mowen, J. C., 2004. Internal benefits of service-worker customer orientation: Job satisfaction, commitment, and organizational citizenship behaviors. The Journal of Marketing 68 (1), 128-146.

Dur, R., Zoutenbier, R., 2014. Working for a good cause. Public Administration Review 74 (2), 144-155.

Englmaier, F., Kolaska, T., Leider, S., 2016. Reciprocity in organizations: Evidence from the uk. CESifo Economic Studies, ifw006.

Englmaier, F., Leider, S., 2012. Contractual and organizational structure with reciprocal agents. American Economic Journal: Microeconomics 42 (2), 146-183.

Fehr, E., Schmidt, K. M., 2006. The economics of fairness, reciprocity and altruismexperimental evidence and new theories. Handbook of the economics of giving, altruism and reciprocity 1, 615-691.

Fershtman, C., Judd, K. L., 1987. Equilibrium incentives in oligopoly. The American Economic Review, 927-940.

Fraja, G., Delbono, F., 1990. Game theoretic models of mixed oligopoly. Journal of Economic Surveys 4 (1), 1-17.

Francois, P., 2000. Public service motivation as an argument for government provision. Journal of Public Economics 78 (3), 275-299. 
Francois, P., 2007. Making a difference. The RAND Journal of Economics 38 (3), 714-732.

Francois, P., Vlassopoulos, M., 2008. Pro-social motivation and the delivery of social services. CESifo Economic Studies 54 (1), 22-54.

Frey, B. S., et al., 1997. Not just for the money. Books.

Ghatak, M., Mueller, H., 2011. Thanks for nothing? not-for-profits and motivated agents. Journal of Public Economics 95 (1), 94-105.

Glazer, A., 2004. Motivating devoted workers. International Journal of Industrial Organization $22(3), 427-440$.

Gneezy, U., Rustichini, A., 2000a. Fine is a price. Journal of Legal Studies 29, 1.

Gneezy, U., Rustichini, A., 2000b. Pay enough or don't pay at all. Quarterly Journal of Economics, 791-810.

Gregg, P., Grout, P. A., Ratcliffe, A., Smith, S., Windmeijer, F., 2011. How important is pro-social behaviour in the delivery of public services? Journal of public economics $95(7), 758-766$.

Hart, O. D., 1983. The market mechanism as an incentive scheme. The Bell Journal of Economics, 366-382.

Hennig-Thurau, T., 2004. Customer orientation of service employees: Its impact on customer satisfaction, commitment, and retention. International Journal of Service Industry Management 15 (5), 460-478.

Hennig-Thurau, T., Thurau, C., 2003. Customer orientation of service employees-toward a conceptual framework of a key relationship marketing construct. Journal of Relationship Marketing 2 (1-2), 23-41.

Hermalin, B. E., 1994. Heterogeneity in organizational form: Why otherwise identical firms choose different incentives for their managers. The RAND Journal of Economics, $518-537$.

Hogan, J., Hogan, R., Busch, C. M., 1984. How to measure service orientation. Journal of Applied Psychology 69 (1), 167.

Ikenwilo, D., Scott, A., 2007. The effects of pay and job satisfaction on the labour supply of hospital consultants. Health Economics 16 (12), 1303-1318.

Imas, A., 2014. Working for the "warm glow": On the benefits and limits of prosocial incentives. Journal of Public Economics 114, 14-18.

Jaimovich, E., Rud, J. P., 2014. Excessive public employment and rent-seeking traps. Journal of Development Economics 106, 144-155. 
Kohli, A. K., Jaworski, B. J., 1990. Market orientation: the construct, research propositions, and managerial implications. The Journal of Marketing, 1-18.

Konow, J., 2010. Mixed feelings: Theories of and evidence on giving. Journal of Public Economics 94 (3), 279-297.

Laffont, J.-J., Martimort, D., 2001. The theory of incentives: the principal-agent model. Princeton university press.

Leonard, K. L., Masatu, M. C., 2010. Professionalism and the know-do gap: Exploring intrinsic motivation among health workers in tanzania. Health economics 19 (12), 14611477 .

Lilley, A., Slonim, R., 2014. The price of warm glow. Journal of Public Economics 114, $58-74$.

Macchiavello, R., 2008. Public sector motivation and development failures. Journal of Development Economics 86 (1), 201-213.

Manna, E., 2016. Mixed duopoly with customer-oriented employees. Mimeo.

Marini, M. A., Polidori, P., Teobaldelli, D., Zevi, A., 2015. Welfare enhancing coordination in consumer cooperatives under mixed oligopoly. Annals of Public and Cooperative Economics 86 (3), 505-527.

Nett, L., 1993. Mixed oligopoly with homogeneous goods. Annals of Public and Cooperative Economics 64 (3), 367-393.

Ottoni-Wilhelm, M., Vesterlund, L., Xie, H., 2014. Why do people give? testing pure and impure altruism. Tech. rep., National Bureau of Economic Research.

Raith, M., 2003. Competition, risk and managerial incentives. American Economic Review 93 (4), 1425-1436.

Salop, S. C., 1979. Monopolistic competition with outside goods. The Bell Journal of Economics, 141-156.

Saxe, R., Weitz, B. A., 1982. The soco scale: a measure of the customer orientation of salespeople. Journal of marketing research, 343-351.

Scharfstein, D., 1988. Product-market competition and managerial slack. The RAND Journal of Economics, 147-155.

Schmidt, K. M., 1997. Managerial incentives and product market competition. The Review of Economic Studies 64 (2), 191-213.

Sergeant, A., Frenkel, S., 2000. When do customer contact employees satisfy customers? Journal of Service Research 3 (1), 18-34. 
Shields, M. A., Ward, M., 2001. Improving nurse retention in the national health service in england: the impact of job satisfaction on intentions to quit. Journal of health economics 20 (5), 677-701.

Tonin, M., Vlassopoulos, M., 2010. Disentangling the sources of pro-socially motivated effort: A field experiment. Journal of Public Economics 94 (11), 1086-1092.

Tonin, M., Vlassopoulos, M., 2015. Corporate philanthropy and productivity: Evidence from an online real effort experiment. Management Science 61 (8), 1795-1811. 


\section{A Computations and Proofs of the Results}

\section{A.1 Monopoly. Proof of Proposition 1.}

I start considering the case in which there is only one firm in the market. In this case, to guarantee an interior solution, the degree of differentiation of the products $t \in(1,2)$ and $\bar{v}>0 .{ }^{28}$ The equilibrium is determined by backward induction. A customer located at $x$ obtains a utility from purchasing the good from the monopolistic firm equal to: $\bar{v}+q-p-t x$. In the last stage, the demand of the firm is the following:

$$
d=2 x=\frac{2(\bar{v}+q-p)}{t} .
$$

Knowing the demand, the principal maximizes his profits:

$$
\Pi=p\left[\frac{2(\bar{v}+q-p)}{t}\right]-\omega
$$

subject to the agent's participation constraint:

$$
\omega-\frac{1}{2} q^{2}+\theta \bar{U}(q, p) \geq 0
$$

where $\bar{U}$ represents the utility of the average customer purchasing the good from the monopolistic firm:

$$
\bar{U}=\bar{v}+q-p-\frac{t}{2}\left(\frac{\bar{v}+q-p}{t}\right)=\frac{1}{2}(\bar{v}+q-p) .
$$

The participation constraint guarantees that the agent accepts the contract. The lowest wage that satisfies the participation constraint just covers the cost of effort incurred by the agent minus the direct benefits he derives from his customer orientation:

$$
\omega=\frac{1}{2} q^{2}-\theta \bar{U}(q, p)
$$

Substituting equation (15) into equation (13), profits can be rewritten as:

$$
\Pi=p\left[\frac{2(\bar{v}+q-p)}{t}\right]-\frac{1}{2} q^{2}+\frac{\theta}{2}(\bar{v}+q-p) .
$$

The first order conditions with respect to the price and quality are respectively equal to:

$$
\begin{aligned}
& \frac{\partial \Pi}{\partial p}=0 \quad \Leftrightarrow \quad 2\left(\frac{\bar{v}+q-p}{t}\right)-\frac{2 p}{t}-\frac{\theta}{2}=0 ; \\
& \frac{\partial \Pi}{\partial q}=0 \quad \Leftrightarrow \quad \frac{2 p}{t}-q+\frac{\theta}{2}=0 .
\end{aligned}
$$

\footnotetext{
${ }^{28}$ The lower and the upper limits on $t$ are such that the principal attains non-negative profits and the customers derive a non-negative utility.
} 
In order to prove that the profit function is concave and has a strict global maximum:

$$
\frac{\partial^{2} \Pi}{\partial p^{2}}=-\frac{4}{t}<0 ; \quad \frac{\partial^{2} \Pi}{\partial q^{2}}=-1<0 ; \quad \frac{\partial^{2} \Pi}{\partial p \partial q}=\frac{2}{t} ; \quad \frac{\partial^{2} \Pi}{\partial q \partial p}=\frac{2}{t} .
$$

The Hessian matrix is:

$$
H=\left(\begin{array}{cc}
-\frac{4}{t} & \frac{2}{t} \\
\frac{2}{t} & -1
\end{array}\right)
$$

Notice that it is symmetric and all the leading principal minors have alternate signs:

$$
-\frac{4}{t}<0,-1<0
$$

and:

$$
\left(-\frac{4}{t}\right)(-1)-\left(\frac{4}{t^{2}}\right)=\frac{4(t-1)}{t^{2}}>0 .
$$

Hence, the Hessian matrix is negative definite.

Solving the system of equations (17) yields

$$
\begin{array}{r}
q=\frac{\bar{v}}{t-1}+\frac{t \theta}{4(t-1)} \\
p=\frac{t \bar{v}}{2(t-1)}+\frac{t \theta(2-t)}{8(t-1)}
\end{array}
$$

In stage 1 , the monopolistic firm decides whether to hire a customer-oriented agent with $\theta=\bar{\theta}>0$ or a selfish agent with $\theta=0$. If the firm hires a selfish $(S)$ or a customer-oriented $(M)$ agent, the optimal levels of quality are:

$$
q^{S}=\frac{\bar{v}}{(t-1)}<q^{S}+\bar{\theta}\left[\frac{t}{4(t-1)}\right]=q^{M},
$$

whereas the prices are:

$$
p^{S}=\frac{t \bar{v}}{2(t-1)}<p^{S}+\bar{\theta}\left[\frac{t(2-t)}{8(t-1)}\right]=p^{M} .
$$

Substituting the optimal levels of quality and price into equation (15), the equilibrium wage is derived:

$$
\omega^{S}=\frac{1}{2}\left[\frac{\bar{v}}{(t-1)}\right]^{2}>\omega^{S}-t \bar{\theta}\left[\frac{8(2-t) \bar{v}+t \bar{\theta}(3-2 t)}{32(t-1)^{2}}\right]=\omega^{M} .
$$

And in stage 4, the demand is realized

$$
d^{S}=\frac{\bar{v}}{(t-1)}<d^{S}+\bar{\theta}\left[\frac{t}{4(t-1)}\right]=d^{M},
$$

and the principal obtains the following profits:

$$
\Pi^{S}=\frac{\bar{v}^{2}}{2(t-1)}<\Pi^{S}+\frac{t \bar{\theta}(8 \bar{v}+t \bar{\theta})}{32(t-1)}=\Pi^{M}
$$




\section{A.2 Competition and Agents' Motivation}

To guarantee an interior solution the following assumption is made.

Assumption 1. The parameters fulfill the following conditions:

- $t \in\left(\frac{1}{2}, \frac{2}{3}(\bar{v} n+1)\right]$;

- $\bar{v} \in\left[0, \frac{2-4 n \bar{\theta}+5 n t \bar{\theta}-3 n^{2} t \bar{\theta}^{2}}{4 n^{2} \bar{\theta}}\right]$;

- $\bar{\theta} \in\left(0, \bar{\theta}_{\text {max }}\right] \quad$ with $\quad \bar{\theta}_{\text {max }}=\frac{(5 t-4)+\sqrt{(5 t-4)^{2}+24 t}}{6 n t}$.

The lower and the upper limits on $t$ are set such that the principals attain non-negative profits and the customers derive a non-negative utility. Customers' valuation $\bar{v}$ must lie in the interval specified above otherwise the customer-oriented agents would earn negative wages. Finally, for $\bar{v}$ to be non-negative, the agents' customer orientation $\bar{\theta}$ cannot be higher than its upper bound.

The model is solved under the assumption that the market is covered. Therefore, the customers' participation constraint is satisfied irrespective of whether firms hire customeroriented or selfish employees. The utility of the marginal customer buying the service for firm $i$ is:

$$
\begin{aligned}
U_{i l} & =\bar{v}+q_{i}-p_{i}-t x_{i l} \\
& =\bar{v}+q_{i}-p_{i}-\frac{t}{2} d_{i}
\end{aligned}
$$

If firms end up hiring selfish employees, the marginal customer will obtain an utility of:

$$
U_{i l}^{S}=\bar{v}+\frac{1}{n}-\frac{t}{n}-\frac{t}{2 n}
$$

In contrast, if firms end up hiring customer-oriented employees, the marginal customer will obtain a utility of:

$$
U_{i l}^{M}=\bar{v}+\frac{1}{n}-\left(\frac{t}{n}-\frac{3}{4} t \bar{\theta}\right)-\frac{t}{2 n}
$$

If the number of firms in the market is exogenous, it is simple to see that the marginal customer is always better off when firms hire customer-oriented employees. Then, if the marginal customer gets a non-negative utility when the employees are selfish, this will also be the case when they are customer-oriented. Equation (25) is non-negative if:

$$
\bar{v}+\frac{1}{n}-\frac{3 t}{2 n} \geq 0
$$

This inequality holds when $t \leq \frac{2}{3}(\bar{v} n+1)$ and this is the upper limits on $t$ in Assumption 1. The utility of the marginal customer is non-negative by Assumption 1 and all customers buys a unit of the good/service. 


\section{A.2.1 The Characterization of the Equilibrium when Agents are Self-Interested}

I begin by characterizing the equilibrium when agents are self-interested, i.e. $\theta_{i}=\underline{\theta}=0$.

In the last stage, customers choose from which firm to buy the good. A customer $l$ is indifferent between firm $i$ and $i+1$ if $U_{i l}=U_{i+1 l}$, or equivalently $\bar{v}+q_{i}-p_{i}-t x_{i l}=$ $\bar{v}+q_{i+1}-p_{i+1}-t\left(\frac{1}{n}-x_{i l}\right)$. This implies that $x_{i l}=\frac{1}{2 n}+\frac{\left(q_{i}-q_{i+1}\right)+\left(p_{i+1}-p_{i}\right)}{2 t}$ and similarly $x_{i l^{\prime}}=\frac{1}{2 n}+\frac{\left(q_{i}-q_{i-1}\right)+\left(p_{i-1}-p_{i}\right)}{2 t}$. The demand for firm $i$ is given by $x_{i l}+x_{i l^{\prime}}$, that is:

$$
d_{i}=\frac{1}{n}+\frac{\left[2 q_{i}-q_{i+1}-q_{i-1}\right]+\left[p_{i+1}+p_{i-1}-2 p_{i}\right]}{2 t} .
$$

Since firms are symmetric in the choice of the agents' type, let $q_{i+1}=q_{i-1}=q_{j}$ and $p_{i+1}=p_{i-1}=p_{j}$. I can rewrite equation (27) as:

$$
d_{i}=\frac{1}{n}+\frac{\left[q_{i}-q_{j}\right]+\left[p_{j}-p_{i}\right]}{t} .
$$

Principal $i$ maximizes his profits:

$$
\pi_{i}=p_{i}\left[\frac{1}{n}+\frac{\left(q_{i}-q_{j}\right)+\left(p_{j}-p_{i}\right)}{t}\right]-\omega_{i},
$$

subject to the agent $i$ 's participation constraint:

$$
\omega_{i}-\frac{1}{2} q_{i}^{2} \geq 0
$$

Principal $i$ will set the lowest $\omega_{i}$ which satisfies the participation constraint:

$$
w_{i}=\frac{1}{2} q_{i}^{2}
$$

Substituting equation (30) into equation (29), profits can be rewritten as:

$$
\pi_{i}=p_{i}\left[\frac{1}{n}+\frac{\left(q_{i}-q_{j}\right)+\left(p_{j}-p_{i}\right)}{t}\right]-\frac{1}{2} q_{i}^{2} .
$$

First order conditions:

$$
\begin{aligned}
\frac{\partial \pi_{i}}{\partial p_{i}}=0 \quad & \Leftrightarrow \quad\left[\frac{1}{n}+\frac{\left(q_{i}-q_{j}\right)+\left(p_{j}-p_{i}\right)}{t}\right]-\frac{p_{i}}{t}=0 ; \\
\frac{\partial \pi_{i}}{\partial q_{i}}=0 \quad \Leftrightarrow \quad \frac{p_{i}}{t}-q_{i}=0 . &
\end{aligned}
$$

The first order conditions depend also on the qualities and prices chosen by the rival firms. Since I am considering the case in which rival firms make the same hiring decision, it follows that firm $j$ 's first order conditions mirror those of firm $i$. Therefore, I solve the following system of equations:

$$
\left\{\begin{array}{l}
p_{i}=\frac{t}{2 n}+\frac{q_{i}-q_{j}+p_{j}}{2} \\
p_{j}=\frac{t}{2 n}+\frac{q_{j}-q_{i}+p_{i}}{2} \\
q_{i}=\frac{p_{i}}{t} \\
q_{j}=\frac{p_{j}}{t}
\end{array}\right.
$$


From the first two equations:

$$
p_{i}=\frac{t}{n}+\frac{q_{i}-q_{j}}{3}
$$

Then,

$$
q_{i}=\frac{1}{t}\left(\frac{t}{n}+\frac{q_{i}-q_{j}}{3}\right)=\frac{1}{n}+\frac{q_{i}-q_{j}}{3 t} .
$$

Similarly,

$$
q_{j}=\frac{1}{n}+\frac{q_{j}-q_{i}}{3 t} \Leftrightarrow q_{j} \frac{(3 t-1)}{3 t}=\frac{1}{n}-\frac{q_{i}}{3 t} \Leftrightarrow q_{j}=\frac{1}{n}\left(\frac{3 t}{3 t-1}\right)-\frac{q_{i}}{3 t-1} .
$$

Substituting $q_{j}, q_{i}$ can be rewritten as:

$$
\begin{gathered}
q_{i} \frac{(3 t-1)}{3 t}=\frac{1}{n}-\frac{1}{n}\left(\frac{1}{3 t-1}\right)+\frac{q_{i}}{3 t(3 t-1)} \Leftrightarrow \frac{q_{i}(3 t-1)^{2}}{3 t(3 t-1)}=\frac{3 t-2}{(3 t-1) n}+\frac{q_{i}}{3 t(3 t-1)} \\
\frac{9 t^{2}-6 t}{3 t(3 t-1)} q_{i}=\frac{3 t-2}{(3 t-1) n} \Leftrightarrow q_{i}=\frac{1}{n}=q_{j}
\end{gathered}
$$

The principals elicit quality's levels

$$
q_{S S}^{S}=\frac{1}{n}
$$

with wages

$$
\omega_{S S}^{S}=\frac{1}{2 n^{2}}
$$

The chosen prices are:

$$
p_{S S}^{S}=\frac{t}{n}
$$

A reduction in $t$ leads to a reduction in the prices of both firms. As $t$ goes to 0 the firms offer always more similar products. The firms are more competitive and the prices go down.

Firms share the demand in the market:

$$
d_{S S}^{S}=\frac{1}{n},
$$

and each principal obtains the following profits by hiring a selfish agent:

$$
\pi_{S S}^{S}=\frac{2 t-1}{2 n^{2}} .
$$

The profits obtained by the firms are increasing in $t$ and decreasing in $n$.

\section{A.2.2 Characterization of the Equilibrium when Agents are Customer-Oriented}

I determine the equilibrium when all agents are customer-oriented, i.e. $\theta_{i}=\bar{\theta}>0$.

Firms are symmetric in the agents' customer orientation and the demand for firm $i$ is equal to:

$$
d_{i}=\frac{1}{n}+\frac{\left[q_{i}-q_{j}\right]+\left[p_{j}-p_{i}\right]}{t}
$$


Principal $i$ maximizes his profits:

$$
\pi_{i}=p_{i}\left(\frac{1}{n}+\frac{\left(q_{i}-q_{j}\right)+\left(p_{j}-p_{i}\right)}{t}\right)-\omega_{i}
$$

subject to the agent $i$ 's participation constraint:

$$
\omega_{i}-\frac{1}{2} q_{i}^{2}+\overline{\theta U}_{i}\left(q_{i}, p_{i}\right) \geq 0 .
$$

The lowest wage that satisfies the agent $i$ 's participation constraint is:

$$
\omega_{i}=\frac{1}{2} q_{i}^{2}-\overline{\theta U}_{i}\left(q_{i}, p_{i}\right)
$$

where the average customers' utility from buying a product from firm $i$ is:

$$
\bar{U}_{i}=\left[\bar{v}+q_{i}-p_{i}-\frac{t}{4}\left(\frac{1}{n}+\frac{\left(q_{i}-q_{j}\right)+\left(p_{j}-p_{i}\right)}{t}\right)\right]
$$

Thus, equation (39) can be rewritten in the following way:

$$
\pi_{i}=p_{i}\left(\frac{1}{n}+\frac{\left(q_{i}-q_{j}\right)+\left(p_{j}-p_{i}\right)}{t}\right)-\frac{1}{2} q_{i}^{2}+\bar{\theta}\left[\bar{v}+q_{i}-p_{i}-\frac{t}{4}\left(\frac{1}{n}+\frac{\left(q_{i}-q_{j}\right)+\left(p_{j}-p_{i}\right)}{t}\right)\right] .
$$

First order conditions:

$$
\begin{aligned}
& \frac{\partial \pi_{i}}{\partial p_{i}}=0 \quad \Leftrightarrow \quad\left[\frac{1}{n}+\frac{\left(q_{i}-q_{j}\right)+\left(p_{j}-p_{i}\right)}{t}\right]-\frac{p_{i}}{t}-\frac{3}{4} \bar{\theta}=0 \\
& \frac{\partial \pi_{i}}{\partial q_{i}}=0 \quad \Leftrightarrow \quad \frac{p_{i}}{t}-q_{i}+\frac{3}{4} \bar{\theta}=0
\end{aligned}
$$

Following the same argument developed when the agents are all selfish, I solve this system of equations:

$$
\left\{\begin{array}{l}
p_{i}=\frac{t}{2 n}+\frac{q_{i}-q_{j}+p_{j}}{2}-\frac{3}{8} t \bar{\theta} \\
p_{j}=\frac{t}{2 n}+\frac{q_{j}-q_{i}+p_{i}}{2}-\frac{3}{8} t \bar{\theta} \\
q_{i}=\frac{p_{i}}{t}+\frac{3}{4} \bar{\theta} \\
q_{j}=\frac{p_{j}}{t}+\frac{3}{4} \bar{\theta}
\end{array}\right.
$$

From the first two equations:

$$
p_{i}=\frac{t}{n}+\frac{q_{i}-q_{j}}{3}-\frac{3}{4} t \bar{\theta}
$$

Then,

$$
q_{i}=\frac{1}{t}\left(\frac{t}{n}+\frac{q_{i}-q_{j}}{3}-\frac{3}{4} t \bar{\theta}\right)+\frac{3}{4} \bar{\theta}=\frac{1}{n}+\frac{q_{i}-q_{j}}{3 t} .
$$

The next steps are equal to the ones shown in the previous subsection when all agents are selfish. 
The optimal levels of quality are:

$$
q_{M M}^{M}=\frac{1}{n}
$$

The prices are given by:

$$
p_{M M}^{M}=t\left(\frac{1}{n}-\frac{3}{4} \bar{\theta}\right) .
$$

When agents are motivated, the price of the products offered by firms is lower than in the previous case, $p_{M M}^{M}<p_{S S}^{S}$. The effect of $\bar{\theta}$ on the price is negative. This fall in price has a positive impact on the customer's utility but negatively affects firms' profits.

The wages are given by:

$$
\omega_{M M}^{M}=\frac{1}{2 n^{2}}-\bar{\theta} \underbrace{\left[\bar{v}+\frac{1}{n}-\left(\frac{t}{n}-\frac{3}{4} t \bar{\theta}\right)-\frac{t}{4 n}\right]}_{\bar{U}^{M}>0} .
$$

The upper limit on $t$ is set such that the customers derive a non-negative utility. The agents' customer orientation has a negative impact on wages. Customer-oriented employees provide a given level of quality for a lower wage. This benefits firms.

Firms share the demand in the market:

$$
d_{M M}^{M}=\frac{1}{n},
$$

and profits are realized:

$$
\pi_{M M}^{M}=\left(\frac{1}{n}\right)\left(\frac{t}{n}-\frac{3}{4} t \bar{\theta}\right)-\left[\frac{1}{2 n^{2}}-\bar{\theta}\left(\bar{v}+\frac{1}{n}-\frac{5}{4} \frac{t}{n}+\frac{3}{4} t \bar{\theta}\right)\right] .
$$

\section{Proof of Proposition 2.}

Assume to the contrary that $\pi_{k l}^{S} \geq \pi_{k l}^{M}$ for some $k, l \in\{S, M\}$. This would imply that there exist $k, l \in\{S, M\}$ such that

$$
d_{k l}^{S} p_{k l}^{S}-\frac{1}{2}\left(q_{k l}^{S}\right)^{2} \geq d_{k l}^{M} p_{k l}^{M}-\frac{1}{2}\left(q_{k l}^{M}\right)^{2}+\bar{\theta} \bar{U}_{k l}^{M} .
$$

If it were the case, principal $i$ would decide to implement the same schedule $\left(q_{k l}^{S}, p_{k l}^{S}\right)$ by hiring customer-oriented agents, but paying them a lower wage. Because $\pi_{k l}^{S}<\pi_{k l}^{S}+\bar{\theta} \bar{U}_{k l}^{S}$, this leads to a contradiction.

\section{A Prisoner's Dilemma. Proof of Proposition 3.}

The profits obtained by hiring self-interested agents are higher than the profits obtained by hiring customer-oriented agents if the following condition is met:

$$
\pi_{S S}^{S}-\pi_{M M}^{M}=\frac{4 \bar{\theta}(2 t-1)-n \bar{\theta}(4 \bar{v}+3 t \bar{\theta})}{4 n}>0
$$


which is the case whenever the following holds:

$$
t>\hat{t}=\frac{4(n \bar{v}+1)}{(8-3 n \bar{\theta})}
$$

The condition of Proposition 3 does not contradict Assumption 1. The threshold value of $t$ above which firms would obtain higher profits by hiring selfish agents is always in the interval if:

$$
\begin{gathered}
\frac{4(n \bar{v}+1)}{(8-3 n \bar{\theta})}<\frac{2}{3}(n \bar{v}+1) \\
12(n \bar{v}+1)<2(n \bar{v}+1)(8-3 n \bar{\theta}) \\
6(n \bar{v}+1)<(n \bar{v}+1)(8-3 n \bar{\theta}) \\
6 n \bar{v}+6<8 n \bar{v}+18-3 n^{2} \bar{v} \bar{\theta}-3 n \bar{\theta} \\
2 n \bar{v}+2-3 n^{2} \bar{v} \bar{\theta}-3 n \bar{\theta}>0 \\
2-3 n \bar{\theta}+2 n \bar{v}-3 n^{2} \bar{v} \bar{\theta}>0 \\
2-3 n \bar{\theta}+n \bar{v}(2-3 n \bar{\theta})>0 \\
(2-3 n \bar{\theta})(1+n \bar{v})>0
\end{gathered}
$$

That is always the case by Assumption $1 .^{29}$ This means that it is always possible to find values of the parameters such that the prisoners' dilemma arises.

\section{A.3 Quality-Oriented Employees. Proof of Proposition 4}

The utility function of a motivated agent who only cares about quality and works in firm $i$ is:

$$
\hat{V}_{i}=\omega_{i}-\frac{1}{2} q_{i}^{2}+\bar{\theta} q_{i}
$$

Firm $i$ maximizes its profit function:

$$
\pi_{i}=p_{i}\left[\frac{1}{n}+\frac{\left(q_{i}-q_{j}\right)+\left(p_{j}-p_{i}\right)}{t}\right]-\omega_{i}
$$

subject to the employees' participation constraint:

$$
\omega_{i}-\frac{1}{2} q_{i}^{2}+\bar{\theta} q_{i} \geq 0
$$

Principal $i$ will set the lowest $\omega_{i}$ that satisfies the participation constraint:

$$
\omega_{i}=\frac{1}{2} q_{i}^{2}-\bar{\theta} q_{i}
$$

\footnotetext{
${ }^{29}$ Notice that if the number of the firms increase, the upper limit for $\bar{\theta}$ to obtain an interior solution decreases. The product $n \bar{\theta}$ must be always lower than $\frac{2}{3}$.
} 
Substituting the previous equation into the maximization problem of firm $i$, profits can be rewritten as:

$$
\pi_{i}=p_{i}\left[\frac{1}{n}+\frac{\left(q_{i}-q_{j}\right)+\left(p_{j}-p_{i}\right)}{t}\right]-\frac{1}{2} q_{i}^{2}+\bar{\theta} q_{i}
$$

First-order conditions are:

$$
\begin{gathered}
\frac{\partial \pi_{i}}{\partial p_{i}}=0 \Leftrightarrow\left[\frac{1}{n}+\frac{\left(q_{i}-q_{j}\right)+\left(p_{j}-p_{i}\right)}{t}\right]-\frac{p_{i}}{t}=0 \\
\frac{\partial \pi_{i}}{\partial q_{i}}=0 \Leftrightarrow \frac{p_{i}}{t}-q_{i}+\bar{\theta}=0
\end{gathered}
$$

Since firms are symmetric, firm $j$ 's first order conditions mirror those of firm $i$. Therefore, I have to solve the following system of equations:

$$
\left\{\begin{array}{l}
p_{i}=\frac{t}{2 n}+\frac{q_{i}-q_{j}+p_{j}}{2} \\
p_{j}=\frac{t}{2 n}+\frac{q_{j}-q_{i}+p_{i}}{2} \\
q_{i}=\frac{p_{i}}{t}+\bar{\theta} \\
q_{j}=\frac{p_{j}}{t}+\bar{\theta}
\end{array}\right.
$$

From the first two equations:

$$
p_{i}=\frac{t}{n}+\frac{q_{i}-q_{j}}{3}
$$

Then,

Similarly,

$$
\begin{aligned}
q_{i} & =\frac{1}{t}\left(\frac{t}{n}+\frac{q_{i}-q_{j}}{3}\right)+\bar{\theta} \\
& =\frac{1}{n}+\frac{q_{i}-q_{j}}{3 t}+\bar{\theta} .
\end{aligned}
$$

$$
\begin{aligned}
q_{j} & =\frac{1}{n}+\frac{q_{j}-q_{i}}{3 t}+\bar{\theta} \\
& =\left(\frac{1}{n}+\bar{\theta}-\frac{q_{i}}{3 t}\right)\left(\frac{3 t}{3 t-1}\right) \\
& =\left(\frac{1}{n}+\bar{\theta}\right)\left(\frac{3 t}{3 t-1}\right)-\frac{q_{i}}{3 t-1} .
\end{aligned}
$$

Substituting $q_{j}, q_{i}$ can be rewritten as:

$$
\begin{aligned}
q_{i} \frac{(3 t-1)}{3 t} & =\left(\frac{1}{n}+\bar{\theta}\right)-\left(\frac{1}{n}+\bar{\theta}\right)\left(\frac{1}{3 t-1}\right)+\frac{q_{i}}{3 t(3 t-1)} \\
\frac{q_{i}(3 t-1)^{2}}{3 t(3 t-1)} & =\left(\frac{1}{n}+\bar{\theta}\right)\left(\frac{3 t-2}{3 t-1}\right)+\frac{q_{i}}{3 t(3 t-1)} \\
\frac{9 t^{2}-6 t}{3 t(3 t-1)} q_{i} & =\left(\frac{1}{n}+\bar{\theta}\right)\left(\frac{3 t-2}{3 t-1}\right) \\
{\left[\frac{3 t(3 t-2)}{3 t(3 t-1)}\right] q_{i} } & =\left(\frac{1}{n}+\bar{\theta}\right)\left(\frac{3 t-2}{3 t-1}\right) \\
q_{i} & =\frac{1}{n}+\bar{\theta}
\end{aligned}
$$


The unique solution is the symmetric equilibrium in which each firm elicits the following quality

$$
\hat{q}_{M M}^{M}=\frac{1}{n}+\bar{\theta}
$$

with wages

$$
\hat{\omega}_{M M}^{M}=\frac{1}{2 n^{2}}-\frac{\bar{\theta}^{2}}{2} .
$$

The chosen prices are:

$$
\hat{p}_{M M}^{M}=\frac{t}{n} .
$$

Firms share the demand in the market:

$$
\hat{d}_{M M}^{M}=\frac{1}{n}
$$

and each principal obtains the following profits by hiring a quality-oriented employee:

$$
\hat{\pi}_{M M}^{M}=\frac{2 t-1}{2 n^{2}}+\frac{\bar{\theta}^{2}}{2} .
$$

The profits increase with $t$ and $\bar{\theta}$, but decrease with $n$. Firms are always better off hiring quality-oriented employees.

\section{A.4 Endogenous Market Structure}

When agents are self-interested, the number of firms is equal to:

$$
\begin{gathered}
n^{S}=\left\lfloor\hat{n}^{S}\right\rfloor ; \\
\text { where } \hat{n}^{S}=\frac{\sqrt{(2 t-1)}}{\sqrt{2 F}} .
\end{gathered}
$$

In the above equation, $n^{S}$ is the greatest integer less than or equal to $\hat{n}^{S} \cdot{ }^{30}$

Remark 6. When agents are self-interested, the number of the firms increases with the degree of product differentiation $t$ and decreases with the cost of entry $F$.

Proof. When all agents are selfish, profits are:

$$
\pi_{S S}^{S}=\frac{(2 t-1)}{2 n^{2}}-F
$$

The derivative of the previous equation with respect to $n$ can be written as:

$$
-\frac{(2 t-1)}{n^{3}}<0
$$

where the term is negative because of Assumption 1. Hence profits are decreasing in $n$. Moreover, profits are decreasing in $F$ and increasing in $t$. Hence, $n$ must be decreasing in $F$ and increasing in $t$.

\footnotetext{
${ }^{30}$ Notice that due to the integer problem, the profits firms can attain may be slightly higher than 0.
} 
A lower $t$ means that products are more substitutable leading to lower equilibrium prices and profits. Similarly, it is straightforward that a reduction in the fix cost $F$ increases the number of the firms leading to a reduction in profits.

The employees' customer orientation has an impact on the profits obtained by firms, and then on the number of firms present in the market. When employees are customeroriented, the number of the firms is equal to:

$$
\begin{gathered}
n^{M}=\left\lfloor\widehat{n}^{M}\right\rfloor \\
\text { where } \widehat{n}^{M}=\frac{\bar{\theta}(2 t-1)+\sqrt{2(2 t-1)\left(4 F-4 \bar{v} \bar{\theta}-2 \bar{\theta}^{2}+t \bar{\theta}^{2}\right)}}{\left(-4 F+4 \bar{v} \bar{\theta}+3 t \bar{\theta}^{2}\right)} .
\end{gathered}
$$

In the above equation, $n^{M}$ is the greatest integer less than or equal to $\widehat{n}^{M}$.

Remark 7. When agents are customer-oriented, the number of the firms increases with the degree of product differentiation $t$, with the cost of entry $F$, and increases with $\bar{v}$. The impact of the agents' customer orientation $\bar{\theta}$ is ambiguous.

Proof. When all agents are customer-oriented, profits are:

$$
\pi_{M M}^{M}=\left(\frac{1}{n}\right)\left(\frac{4 t-3 n t \bar{\theta}}{4 n}\right)-\frac{1}{2 n^{2}}+\bar{\theta}\left[\bar{v}+\frac{1}{n}-\left(\frac{t}{n}-\frac{3}{4} t \bar{\theta}\right)-\frac{t}{4 n}\right]-F .
$$

The derivative of the previous equation with respect to $n$ can be written as:

$$
-\frac{(1-n \bar{\theta})(2 t-1)}{\left(n^{3}\right)}<0
$$

where the overall effect is negative due to Assumption 1. Hence profits are decreasing in $n$. Moreover, profits are decreasing in $F$ and increasing in $t$ and $\bar{v}$. Hence $n$ must be decreasing in $F$ and increasing in $t$ and $\bar{v}$.

The agent's customer orientation $\bar{\theta}$ has a countervailing effect on the number of firms. On the one hand, a high customer orientation reduces the price. The reduction in the price has a negative impact on the profits and then on the number of firms. On the other hand, high customer orientation reduces the wage. This effect has a positive impact on the profits and then on the number of firms.

Akin to the previous case, when products are more substitutable (lower $t$ ) the equilibrium prices decrease leading to a reduction in gross profits. A reduction in the fix cost $F$ increases the number of firms leading to a reduction in gross profits. In addition, a high valuation of the good $\bar{v}$ has a positive impact on the profits (due to a reduction in the wage) and on the number of firms. The effect of the agents' customer orientation on the number of firms is ambiguous. If the negative impact on the revenues (reduction in the price) is greater than the positive impact due to the reduction in the costs (reduction in 
the wage), the agents' customer orientation has a negative impact on the number firms. Otherwise, it impacts positively on the number of firms.

Proof of Remark 1. Comparing the number of firms obtained in the two different cases, I find that when the prisoners' dilemma occurs $n^{S} \geq n^{M}$. In this case, the profits obtained by hiring selfish individuals are higher than the profits obtained by hiring customer-oriented employees, i.e. $\pi_{S S}^{S}>\pi_{M M}^{M}$. As a result, the number of firms in the market is higher or equal to the number of firms when agents are customer-oriented. In this case, customer orientation has a countervailing effect on the customers' utility due to a reduction in the number of firms and to a reduction in the price charged by the firms. It not immediate to see which effect dominates. Remember that the average customer's utility derived from buying a product from firm $i$ when all agents are selfish and when all agents are customer-oriented are equal to the following, respectively:

$$
\bar{U}^{S}=\bar{v}+\frac{1}{n^{S}}-\frac{5 t}{4 n^{S}} ; \quad \bar{U}^{M}=\bar{v}+\frac{1}{n^{M}}-\frac{5 t}{4 n^{M}}+\frac{3}{4} t \bar{\theta} .
$$

Comparing the two equations, the following result is obtained:

$$
\bar{U}^{M}>\bar{U}^{S} \text { if }\left(\frac{1}{n^{M}}-\frac{1}{n^{S}}\right)\left(1-\frac{5}{4} t\right)+\frac{3}{4} t \bar{\theta}>0 .
$$

This is the case when:

$$
\bar{\theta}>\left(\frac{1}{n^{S}}-\frac{1}{n^{M}}\right)\left(\frac{4-5 t}{3 t}\right) .
$$

When the prisoners' dilemma occurs, the gross profits obtained by hiring self-interested agents are higher than those obtained by hiring customer-oriented agents, and so is the number of firms, i.e. $n^{S} \geq n^{M}$. When this happens

$$
\left(\frac{1}{n^{S}}-\frac{1}{n^{M}}\right) \leq 0
$$

Notice that equation (55) is always satisfied when $t<\frac{4}{5}$. Otherwise, equation (55) is satisfied only if the agent's customer orientation is sufficiently high. When the number of firms is endogenous, the agents' customer orientation may have a negative impact on the customers' utility. This happens when $t$ is sufficiently high and $\bar{\theta}$ is sufficiently low.

\section{B Robustness Checks}

\section{B.1 Asymmetric Information on $\bar{\theta}$}

If principals offer different contracts designed for different types of agents, they would pay an information rent to customer-oriented agents in order to attain separation of types. The $\bar{\theta}$-agents would benefit from an information rent stemming from their ability to mimic the selfish agents. For the $\bar{\theta}$-agents the incentive constraints are binding, whereas for the $\underline{\theta}$-agents the participation constraints bind. 
As long as there is perfect competition in the labor market, i.e. there are an infinite number of agents of both types, principals are better off offering a contract just to customer-oriented agents. Each principal has only to satisfy the participation constraint of the customer-oriented agent:

$$
V^{M}=\omega^{M}-\frac{1}{2} q^{2 M}+\bar{\theta} \bar{U}^{M} \geq 0 .
$$

And the selfish agents never accept the contract because they obtain a negative utility:

$$
V^{S}=V\left(\left(\omega^{M}, q^{M}\right), \underline{\theta}\right)=\frac{1}{2} q^{2 M}-\bar{\theta} \bar{U}^{M}-\frac{1}{2} q^{2 M}=-\bar{\theta} \bar{U}^{M}<0 .
$$

As a result, for a value of $t$ sufficiently high firms are trapped in a prisoner's dilemma.

\section{B.2 Alternative Specification of the Employees' Customer Ori- entation}

If a customer-oriented agent who works in firm $i$ cares about the overall surplus of the customers who buy the product from firm $i$, his utility is:

$$
\tilde{V}_{i}=\omega_{i}-\frac{1}{2} q_{i}^{2}+\theta_{i} C S_{i}
$$

where $C S_{i}$ is the sum of the customers' surplus buying the product from firm $i$ with $x_{i l}$ be the mass of customers on its left and $x_{i l^{\prime}}$ be the mass of customers on its right. It can be written as:

$$
\begin{aligned}
C S_{i} & =\int_{0}^{x_{i l}}\left[\left(\bar{v}+q_{i}-p_{i}\right)-t x\right] d x+\int_{0}^{x_{i l^{\prime}}}\left[\left(\bar{v}+q_{i}-p_{i}\right)-t x\right] d x \\
& =\left(\bar{v}+q_{i}-p_{i}\right)\left(x_{i l}+x_{i l^{\prime}}\right)-t \int_{0}^{x_{i l}} x d x-t \int_{0}^{x_{i l^{\prime}}} x d x \\
& =\left(\bar{v}+q_{i}-p_{i}\right)\left(x_{i l}+x_{i l^{\prime}}\right)-\frac{t}{2}\left[x_{i l}^{2}+x_{i l^{\prime}}^{2}\right]
\end{aligned}
$$

Remember that the demand for firm $i$ is given by $x_{i l}+x_{i l^{\prime}}$.

Proposition 2 continues to hold. An employer could pay a lower salary to a customeroriented employee to implement the same quality-price pair requested from a selfish employee. However, in what follows I show that all firms would obtain higher profits if they colluded to hiring selfish employees. To show this result, I determine the equilibrium when all employees are customer-oriented.

Principal $i$ maximizes its profits:

$$
\pi_{i}=p_{i}\left(\frac{1}{n}+\frac{q_{i}-q_{j}+p_{j}-p_{i}}{t}\right)-\omega_{i}
$$


subject to the agent's $i$ participation constraint $\tilde{V}_{i} \geq 0$. Firm $i$ will set the lowest $\omega_{i}$ that satisfies the participation constraint:

$$
\begin{aligned}
\omega_{i} & =\frac{1}{2} q_{i}^{2}-\bar{\theta} C S_{i} \\
& =\frac{1}{2} q_{i}^{2}-\bar{\theta}\left[\left(\bar{v}+q_{i}-p_{i}\right) d_{i}-t \frac{d_{i}^{2}}{4}\right] \\
& =\frac{1}{2} q_{i}^{2}-\bar{\theta} d_{i}\left[\left(\bar{v}+q_{i}-p_{i}\right)-\frac{t}{4} d_{i}\right] \\
& =\frac{1}{2} q_{i}^{2}-\bar{\theta}\left(\frac{1}{n}+\frac{q_{i}-q_{j}+p_{j}-p_{i}}{t}\right)\left(\bar{v}+q_{i}-p_{i}\right)+\frac{t}{4} \bar{\theta}\left(\frac{1}{n}+\frac{q_{i}-q_{j}+p_{j}-p_{i}}{t}\right)^{2}
\end{aligned}
$$

Firm $i$ 's profits can be rewritten as:

$$
\begin{aligned}
\pi_{i} & =p_{i}\left(\frac{1}{n}+\frac{q_{i}-q_{j}+p_{j}-p_{i}}{t}\right)+ \\
& -\left[\frac{1}{2} q_{i}^{2}-\bar{\theta}\left(\frac{1}{n}+\frac{q_{i}-q_{j}+p_{j}-p_{i}}{t}\right)\left(\bar{v}+q_{i}-p_{i}\right)+\frac{t}{4} \bar{\theta}\left(\frac{1}{n}+\frac{q_{i}-q_{j}+p_{j}-p_{i}}{t}\right)^{2}\right]
\end{aligned}
$$

First order conditions are:

$$
\begin{aligned}
\frac{\partial \pi_{i}}{\partial p_{i}}=0 \Leftrightarrow\left[\frac{1}{n}+\frac{\left(q_{i}-q_{j}\right)+\left(p_{j}-p_{i}\right)}{t}\right]-\frac{p_{i}}{t}-\bar{\theta}\left[\frac{1}{2}\left(\frac{1}{n}+\frac{q_{i}-q_{j}+p_{j}-p_{i}}{t}\right)+\frac{\left(v+q_{i}-p_{i}\right)}{t}\right]=0 \\
\frac{\partial \pi_{i}}{\partial q_{i}}=0 \Leftrightarrow \frac{p_{i}}{t}-q_{i}+\bar{\theta}\left[\frac{1}{2}\left(\frac{1}{n}+\frac{q_{i}-q_{j}+p_{j}-p_{i}}{t}\right)+\frac{1}{t}\left(\bar{v}+q_{i}-p_{i}\right)\right]=0
\end{aligned}
$$

To obtain the optimal levels of quality and price, I solve the following system of equations:

$$
\left\{\begin{array}{l}
p_{i}=\frac{\left(t+n p_{j}-n q_{j}\right)(2-\bar{\theta})+n q_{i}(2-3 \bar{\theta})-2 n \bar{v} \bar{\theta}}{n(4-3 \bar{\theta}} \\
p_{j}=\frac{\left(t+n p_{i}-n q_{i}\right)(2-\bar{\theta})+n q_{j}(2-3 \bar{\theta})-2 n \bar{v} \bar{\theta}}{n(4-3 \bar{\theta})} \\
q_{i}=\frac{n p_{i}(2-3 \bar{\theta})+n p_{j} \bar{\theta}-n q_{j} \bar{\theta}+t \bar{\theta}+2 n \bar{v} \bar{\theta}}{n(2 t-3 \bar{\theta})} \\
q_{j}=\frac{n p_{j}(2-3 \bar{\theta})+n p_{i} \bar{\theta}-n q_{i} \bar{\theta}+t \bar{\theta}+2 n \bar{v} \bar{\theta}}{n(2 t-3 \bar{\theta})}
\end{array}\right.
$$

And I find that the quality provided by each firm is $\tilde{q}_{i}=\frac{1}{n}$. It does not depend on $\bar{\theta}$ and is equal to the one found when I have considered the average customers' utility.

Each firm charges the following price:

$$
\tilde{p}_{i}=\frac{t(2-\bar{\theta})}{2 n(1-\bar{\theta})}-\frac{\bar{\theta}}{n}\left[\frac{1+\bar{v} n}{(1-\bar{\theta})}\right] .
$$

Again, an increase in the employees' customer orientation reduces the prices charged by the firms, and this impacts negatively on profits.

Customer-oriented employees receive a wage of:

$$
\tilde{\omega}_{i}=\frac{2-6 \bar{\theta}+5 t \bar{\theta}-4 n \bar{v} \bar{\theta}-3 t \bar{\theta}^{2}}{4 n^{2}(1-\bar{\theta})}
$$


At the same time, an increase in $\bar{\theta}$ has a negative impact on wages.

Firms share the demand in the market $\tilde{d}_{i}=\frac{1}{n}$ and profits are realized:

$$
\tilde{\pi}_{i}=\left[\left(\frac{t(2-\bar{\theta})}{2 n(1-\bar{\theta})}\right)-\frac{\bar{\theta}}{n}\left(\frac{1+\bar{v} n}{(1-\bar{\theta})}\right)\right]\left(\frac{1}{n}\right)-\left(\frac{2-6 \bar{\theta}+5 t \bar{\theta}-4 n \bar{v} \bar{\theta}-3 t \bar{\theta}^{2}}{4 n^{2}(1-\bar{\theta})}\right)
$$

After some simple computations, profits can be rewritten as:

$$
\tilde{\pi}_{i}=\frac{4 t-2-3 t \bar{\theta}}{4 n^{2}}
$$

All firms obtain higher profits by hiring selfish rather than customer-oriented employees if:

$$
\tilde{\pi}^{S}-\tilde{\pi}^{M}=\frac{2 t-1}{2 n^{2}}-\frac{4 t-2-3 t \bar{\theta}}{4 n^{2}}=\frac{3 t \bar{\theta}}{4 n^{2}}>0
$$

which is always the case. The main results of the paper still hold and they are even more robust under this specification. In particular, the negative impact on the price of the employees' customer orientation always outweighs the negative impact on the wage. As a result, the employees' customer orientation has a negative impact on the firms' profits and firms are always trapped in a prisoners' dilemma.

\section{B.3 Limited Supply of Customer-Oriented Employees}

As a robustness check, I consider the case in which the number of customer-oriented employees is lower than the number of firms in the market. Let $m$ be the number of customer-oriented employees with $m<n$. In this case, an employee's outside option will depend on the offer he receives from the other firms in the market.

For the sake of simplicity, I assume that there are just three firms and three employees in the market. Just one employee is customer-oriented with $\bar{\theta}>0$, i.e. $m=1$, whereas the other employees in the market are selfish with $\underline{\theta}=0 .{ }^{31}$ Suppose that firm 1 is the firm which ends up hiring the customer-oriented employee. The equilibrium is determined by backward induction.

In stage 4, the customers choose which good to buy and the demand for firm 1 will be:

$$
d_{1}=\frac{1}{3}+\frac{\left(2 q_{1}-q_{2}-q_{3}\right)+\left(p_{2}+p_{3}-2 p_{1}\right)}{2 t}
$$

If firm 1 succeeds in hiring the customer-oriented employee, firms 2 and 3 are "forced" to hire selfish agents and by symmetry $q_{2}=q_{3}=q$ and $p_{2}=p_{3}=p$. Then, the demand for firm 1 can be rewritten as:

$$
d_{1}=\frac{1}{3}+\frac{q_{1}-q+p-p_{1}}{t}
$$

In contrast, the demand for firms 2 and 3 is equal to:

$$
d=\frac{1}{3}+\frac{q-q_{1}+p_{1}-p}{2 t}
$$

\footnotetext{
${ }^{31}$ This case can be easily generalized to the case in which there are $n$ firms and $n$ employees but just one is customer-oriented.
} 
Knowing its demand function, firm 1 chooses the price to maximize its profits, taking qualities and wages as given:

$$
\pi_{1}=p_{1}\left(\frac{1}{3}+\frac{q_{1}-q+p-p_{1}}{t}\right)-\omega_{1}
$$

subject to the following participation constraints:

$$
\begin{aligned}
& \omega_{1}-\frac{1}{2} q_{1}^{2}+\bar{\theta} \bar{U}_{1} \geq 0 \\
& \omega_{1}-\frac{1}{2} q_{1}^{2}+\bar{\theta} \bar{U}_{1} \geq R
\end{aligned}
$$

where $R \geq 0$ represents the customer-oriented employee's outside option that is determined by the competitive offers he receives in the first stage of the game. As the second constraint binds, the principal has to offer a contract that gives the agent a higher expected utility than the one found previously.

In contrast, the rival firms maximize their profits:

$$
\pi=p\left(\frac{1}{3}+\frac{q-q_{1}+p_{1}-p}{2 t}\right)-\omega
$$

subject to the following participation constraint:

$$
\omega-\frac{1}{2} q^{2} \geq 0
$$

First order conditions are:

$$
\begin{aligned}
\frac{\partial \pi_{1}}{\partial p_{1}}=0 \Leftrightarrow-\frac{p_{1}}{t}+\frac{1}{3}+\frac{q_{1}-q+p-p_{1}}{t}-\bar{\theta}=0 \\
\frac{\partial \pi_{1}}{\partial q_{1}}=0 \Leftrightarrow \frac{p_{1}}{t}-q_{1}+\bar{\theta}=0 \\
\frac{\partial \pi}{\partial p}=0 \Leftrightarrow-\frac{p}{2 t}+\frac{1}{3}+\frac{q-q_{1}+p_{1}-p}{2 t}=0 \\
\frac{\partial \pi}{\partial q}=0 \Leftrightarrow \frac{p}{2 t}-q=0
\end{aligned}
$$

To obtain the optimal levels of quality and price, I solve the following system of equations:

$$
\left\{\begin{array}{l}
p_{1}=\frac{t}{6}+\frac{q_{1}-q+p}{2}-\frac{t \bar{\theta}}{2} \\
p=\frac{t}{3}+\frac{q-q_{1}+p_{1}}{2} \\
q_{1}=\frac{p_{1}}{t}+\bar{\theta} \\
q=\frac{p}{2 t}
\end{array}\right.
$$

Firms elicit the following levels of quality:

$$
\begin{aligned}
q_{1} & =\frac{16 t-6+9 t \bar{\theta}}{18(2 t-1)} \\
q & =\frac{20 t-12-9 t \bar{\theta}}{36(2 t-1)}
\end{aligned}
$$


Each firm charges the following price:

$$
\begin{aligned}
p_{1} & =\frac{4 t(8 t-3)+2 t \bar{\theta}(9-12 t)}{36(2 t-1)} \\
p & =\frac{t(20 t-12-9 t \bar{\theta}}{18(2 t-1)}
\end{aligned}
$$

The employee's customer orientation has a negative impact on the price set by each firm. However, this negative impact is higher on firm 1 than on the other firms.

The wages paid to the employees are the following:

$$
\begin{aligned}
\omega_{1}= & \frac{1}{2}\left(\frac{16 t-6+9 t \bar{\theta}}{18(2 t-1)}\right)^{2} \\
& -\bar{\theta}\left[\bar{v}+\frac{16 t-6+9 t \bar{\theta}}{18(2 t-1)}-\left(\frac{4 t(8 t-3)+2 t \bar{\theta}(9-12 t)}{36(2 t-1)}\right)-\frac{t}{2}\left(\frac{16 t-6+9 t \bar{\theta}}{18(2 t-1)}\right)\right]+R \\
\omega= & \frac{1}{2}\left(\frac{20 t-12-9 t \bar{\theta}}{36(2 t-1)}\right)^{2}
\end{aligned}
$$

Notice that, because of competitive pressure, the motivated agent will receive a compensation that consists of the difference in firms' profits, i.e. $R=\pi_{1}-\pi$. In other words, firms 2 and 3 would be willing to pay as much as the profits differential to hire him.

The demand of each firm is:

$$
\begin{aligned}
d_{1} & =\frac{16 t-6+9 t \bar{\theta}}{18(2 t-1)} \\
d & =\frac{20 t-12-9 t \bar{\theta}}{36(2 t-1)}
\end{aligned}
$$

and profits are realized:

$$
\begin{aligned}
\pi_{1}= & \left(\frac{4 t(8 t-3)+2 t \bar{\theta}(9-12 t)}{36(2 t-1)}\right)\left(\frac{16 t-6+9 t \bar{\theta}}{18(2 t-1)}\right)-\frac{1}{2}\left(\frac{16 t-6+9 t \bar{\theta}}{18(2 t-1)}\right)^{2}+ \\
& +\bar{\theta}\left[\bar{v}+\frac{16 t-6+9 t \bar{\theta}}{18(2 t-1)}-\left(\frac{4 t(8 t-3)+2 t \bar{\theta}(9-12 t)}{36(2 t-1)}\right)-\frac{t}{2}\left(\frac{16 t-6+9 t \bar{\theta}}{18(2 t-1)}\right)\right]-R \\
\pi= & \left(\frac{t(20 t-12-9 t \bar{\theta}}{18(2 t-1)}\right)\left(\frac{20 t-12-9 t \bar{\theta}}{36(2 t-1)}\right)-\frac{1}{2}\left(\frac{20 t-12-9 t \bar{\theta}}{36(2 t-1)}\right)^{2}
\end{aligned}
$$

\section{B.4 Different Production Technology}

The condition that satisfies the customers' participation constraint changes. More specifically, $t$ is set in such a way that the customers derive a non-negative utility irrespective of whether firms decide to hire a selfish or a customer-oriented employee. If the marginal 
customer gets a non-negative utility when the employees are selfish, this will also be the case when they are customer-oriented. This is the case when:

$$
U_{i l}^{S}=\bar{v}+\frac{1}{n}-\frac{t}{n}-c-\frac{t}{2 n} \geq 0
$$

The previous inequality holds when $t \leq \frac{2}{3}(\bar{v} n+1-c)$. When this condition is satisfied, all customers buys a unit of the good/service.

Principal $i$ maximizes his profits:

$$
\pi_{i}=\left(p_{i}-c\right)\left(\frac{1}{n}+\frac{\left(q_{i}-q_{j}\right)+\left(p_{j}-p_{i}\right)}{t}\right)-\omega_{i}
$$

subject to the agent $i$ 's participation constraint:

$$
\omega_{i}-\frac{1}{2} q_{i}^{2}+\theta_{i} \bar{U}_{i}\left(q_{i}, p_{i}\right) \geq 0 .
$$

The lowest wage that satisfies the agent $i$ 's participation constraint is:

$$
\omega_{i}=\frac{1}{2} q_{i}^{2}-\theta_{i} \bar{U}_{i}\left(q_{i}, p_{i}\right)
$$

where the average customers' utility from buying a product from firm $i$ is:

$$
\bar{U}_{i}=\left[\bar{v}+q_{i}-p_{i}-\frac{t}{4}\left(\frac{1}{n}+\frac{\left(q_{i}-q_{j}\right)+\left(p_{j}-p_{i}\right)}{t}\right)\right]
$$

Thus, firm $i$ maximizes the following:

$$
\pi_{i}=\left(p_{i}-c\right)\left(\frac{1}{n}+\frac{\left(q_{i}-q_{j}\right)+\left(p_{j}-p_{i}\right)}{t}\right)-\frac{1}{2} q_{i}^{2}+\theta_{i}\left[\bar{v}+q_{i}-p_{i}-\frac{t}{4}\left(\frac{1}{n}+\frac{\left(q_{i}-q_{j}\right)+\left(p_{j}-p_{i}\right)}{t}\right)\right] .
$$

First order conditions:

$$
\begin{gathered}
\frac{\partial \pi_{i}}{\partial p_{i}}=0 \Leftrightarrow\left[\frac{1}{n}+\frac{\left(q_{i}-q_{j}\right)+\left(p_{j}-p_{i}\right)}{t}\right]-\frac{\left(p_{i}-c\right)}{t}-\frac{3}{4} \theta_{i}=0 \\
\frac{\partial \pi_{i}}{\partial q_{i}}=0 \quad \Leftrightarrow \quad \frac{\left(p_{i}-c\right)}{t}-q_{i}+\frac{3}{4} \theta_{i}=0
\end{gathered}
$$

Following the same argument developed when the agents are all selfish, I solve this system of equations:

$$
\left\{\begin{array}{l}
p_{i}=\frac{t}{2 n}+\frac{c}{2}+\frac{q_{i}-q_{j}+p_{j}}{2}-\frac{3}{8} t \theta_{i} \\
p_{j}=\frac{t}{2 n}+\frac{c}{2}+\frac{q_{j}-q_{i}+p_{i}}{2}-\frac{3}{8} t \theta_{i} \\
q_{i}=\frac{\left(p_{i}-c\right)}{t}+\frac{3}{4} \theta_{i} \\
q_{j}=\frac{\left(p_{j}-c\right)}{t}+\frac{3}{4} \theta_{i}
\end{array}\right.
$$

From the first two equations:

$$
p_{i}=\frac{t}{n}+c+\frac{q_{i}-q_{j}}{3}-\frac{3}{4} t \theta_{i} .
$$


Then,

$$
q_{i}=\frac{1}{t}\left(\frac{t}{n}+c+\frac{q_{i}-q_{j}}{3}-\frac{3}{4} t \theta_{i}-c\right)+\frac{3}{4} \bar{\theta}=\frac{1}{n}+\frac{q_{i}-q_{j}}{3 t} .
$$

After some simple computations, each firm provides the following quality:

$$
q_{i}=\frac{1}{n}
$$

The prices are:

$$
p_{i}=t\left(\frac{1}{n}-\frac{3}{4} \theta_{i}\right)+c
$$

The wages are given by:

$$
\omega_{i}=\frac{1}{2 n^{2}}-\theta_{i}\left[\bar{v}+\frac{1}{n}-\left(\frac{t}{n}-\frac{3}{4} t \bar{\theta}\right)-c-\frac{t}{4 n}\right] .
$$

Firms share the demand in the market:

$$
d_{i}=\frac{1}{n}
$$

and profits are realized. In equilibrium, all firms end up hiring customer-oriented employees, i.e. $\theta_{i}=\bar{\theta}>0$, and profits are:

$$
\pi_{M M}^{M}=\left(\frac{1}{n}\right)\left(\frac{t}{n}-\frac{3}{4} t \bar{\theta}+c-c\right)-\left[\frac{1}{2 n^{2}}-\bar{\theta}\left(\bar{v}+\frac{1}{n}-\frac{5}{4} \frac{t}{n}-c+\frac{3}{4} t \bar{\theta}\right)\right] .
$$

In contrast, if all firms would be able to collude hiring selfish employees, i.e. $\theta_{i}=0$, profits are:

$$
\pi_{S S}^{S}=\left(\frac{1}{n}\right)\left(\frac{t}{n}+c-c\right)-\left(\frac{1}{2 n^{2}}\right)
$$

The prisoners' dilemma occurs when $\pi_{S S}^{S}>\pi_{M M}^{M}$. That is when

$$
\left(\frac{1}{n}\right)\left(\frac{t}{n}\right)-\left(\frac{1}{2 n^{2}}\right)>\left(\frac{1}{n}\right)\left(\frac{t}{n}-\frac{3}{4} t \bar{\theta}\right)-\left[\frac{1}{2 n^{2}}-\bar{\theta}\left(\bar{v}+\frac{1}{n}-\frac{5}{4} \frac{t}{n}-c+\frac{3}{4} t \bar{\theta}\right)\right] .
$$

The previous condition is satisfied when:

$$
t>\frac{4(n \bar{v}+1-n c)}{8-3 n \bar{\theta}} .
$$

